\title{
A Iniciativa Yasuní-ITT: uma análise a partir do Modelo de Fluxos Múltiplos
}

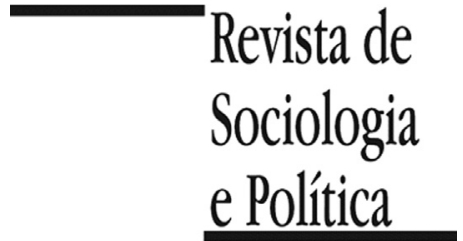

DOI 10.1590/1678-987316245903

\author{
Bruno Milanez e Rodrigo Salles Pereira dos Santos
}

\author{
Resumo
}

\begin{abstract}
Este artigo analisa uma proposta de política ambiental e de recursos naturais, a Iniciativa Yasuní-ITT, através da qual o governo do Equador renunciaria à exploração de reservas de petróleo significativas. Objetiva discutir a iniciativa como uma inovação na agenda de políticas públicas, através da construção social da exploração petrolífera na Amazônia equatoriana como problema público, elaboração de soluções alternativas e seu reconhecimento governamental. O artigo foi baseado na aplicação do Modelo dos Fluxos Múltiplos (MFM) no processo de definição de agenda, a partir de ampla revisão bibliográfica. As informações referentes à Iniciativa foram coletadas, fundamentalmente, na literatura científica, bem como em documentos de instituições e organizações envolvidas em sua formulação. Embora a Iniciativa não tenha sido implementada, sua evolução na agenda permitiu destacar os vínculos entre disputas territoriais locais e questões econômicas nacionais, a possibilidade de compensação econômica e uma moratória da exploração, além de levantar questões relativas à legitimidade política. A articulação desses fluxos foi possível através de uma janela de políticas públicas centrada na questão climática e por agentes como a Presidência, empresas petroleiras, ONGs e movimentos sociais, além de instituições internacionais e outros governos. As principais contribuições à discussão sobre políticas públicas e definição de agenda referem-se: (1) à relevância da combinação de discursos, neste caso morais (biodiversidade, direitos humanos e mudanças climáticas) e econômicos, para a formulação do problema; (2) à forte correlação entre diferentes escalas (nacional e internacional) na compreensão do fluxo político e (3) à concepção processual dos agentes na condução dos fluxos e janelas de políticas públicas, alterando suas capacidades relativas de exercício de poder.
\end{abstract}

PALAVRAS-CHAVE: política pública; modelo de fluxos múltiplos; petróleo; Equador; Yasuní.

Recebido em 3 de Março de 2015. Aceito em 16 de Maio de 2015.

\section{Introdução ${ }^{1}$}

${ }^{1}$ Esse artigo aprofunda a discussão realizada em Milanez (2014). Agradecemos aos comentários e sugestões dos pareceristas anônimos da Revista de Sociologia e Política.
$\mathrm{E}$ ste artigo analisa a Iniciativa Yasuní-ITT, apresentada pelo governo do Equador em 2007. O projeto defendia a ideia de o governo do Equador não explorar parte de suas reservas de petróleo, recebendo, por isso, recursos de países industrializados como compensação pela não emissão de Gases de Efeito Estufa (GEE). A proposta compreendia os campos IshpingoTiputini-Tambococha (ITT), dentro do Parque Nacional de Yasuní (PNY) e na área de influência da Reserva Étnica Waorani (REW), onde estimativas indicavam a existência de 850 milhões de barris de petróleo, quase $25 \%$ das reservas comprovadas do Equador (Acosta 2009). A escolha dos campos ITT para implementação de tal proposta foi devida à grande biodiversidade existente no local, bem como ao fato dos campos estarem em territórios ocupados por comunidades indígenas em isolamento voluntário (Acosta 2014).

O texto lança mão do Modelo dos Fluxos Múltiplos (MFM) como elemento estruturador. Essa escolha se deve por se identificar a capacidade analítica do modelo, principalmente para explicitar alguns elementos específicos relacionados às estratégias adotadas e aos agentes envolvidos. Assim, o artigo argumenta que a transformação da Iniciativa Yasuní-ITT em uma proposta de política reconhecida pelo governo equatoriano se deveu a um conjunto específico de fatores: (1) a combinação de discursos de natureza moral e econômica; (2) a influência do contexto internacional sobre as decisões nacionais e; (3) a 
oportunidade criada pela participação de representantes de movimentos sociais no governo.

Como contribuição conceitual, o artigo é relevante por apresentar algumas reflexões sobre oportunidades de melhoria para o uso do MFM na análise de casos empíricos. Tais reflexões dizem respeito à possibilidade de sua complementação pela perspectiva construtivista, às inter-relações entre fluxo político doméstico e fluxo político internacional e à necessidade de aprofundar as possibilidades criadas pela mobilidade dos agentes entre organizações que pertencem à mesma coalizão política.

Do ponto de vista de sua relevância social, o estudo mostra-se coerente com o atual contexto de reformulação dos marcos legais relacionados às atividades extrativas minerais no Brasil. Em 2010, o Governo Federal iniciou a discussão sobre a reformulação do Código Mineral (Malerba 2012), debate que levou diferentes movimentos sociais a formarem o Comitê Nacional em Defesa dos Territórios frente à Mineração (CNDTM). Este Comitê defendia, entre suas bandeiras, a criação de Áreas Livres de Mineração no Brasil (CNDTM 2013). Da mesma forma, a partir de 2013 foi se intensificando, no Congresso Nacional, o debate sobre a regulamentação da mineração em terras indígenas (Kokubo 2013). Dentro desse contexto, o debate sobre restrição a atividades extrativas minerais foi se intensificando no Brasil sendo, portanto, relevante aprofundar a análise sobre experiências desenvolvidas em outros países. O caso da Iniciativa Yasuní-ITT, nesse sentido, é emblemático, tendo sido usado como exemplo para propostas em diferentes países, levando ao chamado processo de "Yasunização" (Temper et al., 2013).

O debate conceitual da pesquisa é baseado em uma revisão bibliográfica do MFM. As informações referentes à Iniciativa Yasuní-ITT foram coletadas, fundamentalmente, na literatura científica que trata da questão, bem como em documentos elaborados por instituições e organizações envolvidas em sua formulação.

Para apresentar este caso, o texto está estruturado em quatro seções, além dessa introdução. A seção II faz uma breve apresentação do MFM, descrevendo seus elementos constituintes e comentando seus objetivos, pressupostos, potenciais e limitações. Em seguida, é feita a descrição da Iniciativa Yasuní-ITT a partir da estrutura do MFM, sendo considerados, primeiramente o papel dos agentes; esta seção ainda apresenta o desenvolvimento dos três fluxos (problemas, soluções e política), bem como as condições que levaram à abertura e ao fechamento de uma janela de políticas públicas. A Seção IV considera a validade do uso do modelo nesta análise, bem como comenta possíveis desdobramentos do estudo para pesquisas e políticas públicas no contexto brasileiro.

\section{O Modelo dos Fluxos Múltiplos}

\section{II.1. Políticas públicas, agenda setting e poder}

Considera-se, de maneira geral, o estudo da política pública um aspecto importante da Ciência Política (Souza 2006), a despeito de sua definição não desfrutar de consenso. Apesar da natureza contenciosa do campo, é possível certo grau de acordo acerca de algumas de suas propriedades elementares, considerando que políticas públicas remetem a problemas que demandam atenção; se dirigem a objetivos ou situações desejados; são executadas, em última instância, por governos, ainda que sua formulação seja geralmente mais plural; implicam interpretações diversas, mas demandam algum nível de legitimidade e, finalmente, dizem respeito tanto ao que governos decidem fazer quanto ao que escolhem não fazer (Birkland 2015). 
De maneira geral, a pesquisa na área vem recorrendo a ferramentas conceituais disseminadas que, de diferentes maneiras, vêm enfrentando a natureza complexa das políticas públicas. Um desses conceitos-chave é o de ciclo de políticas públicas (policy cycle), entendido como uma sequência de estágios, indo da formulação à avaliação da política pública, e cuja origem remonta ao trabalho de Lasswell (1956).

Ainda que tenha sido amplamente contestado pela ausência de um modelo causal e, consequentemente, por sua insuficiência como arcabouço teórico, o foco totalizante na dinâmica interna da política pública fez do policy cycle uma ferramenta estruturante da abundante variedade de literatura, abarcando instrumentos conceituais e analíticos e estudos empíricos e tendo se tornado "um modelo básico (background) para avaliar e comparar as contribuições (e omissões) específicas das teorias mais recentes do processo político" (Jann \& Wegrich 2007, p.57). Consagrado como uma estrutura de análise empírica elementar das políticas públicas, a partir da "definição de agenda, formulação de política, tomada de decisão, implementação e avaliação (eventualmente conduzindo à conclusão), o ciclo de políticas públicas se tornou o modo convencional de descrever a cronologia de um processo político" (Jann \& Wegrich 2007, p.43).

Enfoca-se, em particular, a problema da definição de agenda, tendo o ciclo de políticas públicas como referencial ampliado. Assim, ao conceber a agenda como "uma coleção de problemas, formas de discernimento de causas, símbolos, soluções e outros elementos de problemas públicos que vêm à atenção dos membros do público e os seus funcionários governamentais", sua definição diz respeito aos processos através dos quais questões específicas são construídas socialmente como problemas públicos, e destes são derivadas propostas alternativas de soluções que "ganham ou perdem atenção pública e da elite" (Birkland 2007, p.63).

Levando em consideração que a definição de questões, problemas e soluções é um processo inerentemente contencioso, dadas as limitações estruturais de escopo da agenda de políticas públicas (Birkland 2007, p. 65), torna-se crucial entender o engajamento dos agentes tanto na conversão de questões em problemas e definição de soluções adequadas quanto no bloqueio das oportunidades de fazer o mesmo por parte de agentes concorrentes.

De fato, o problema da definição da agenda de políticas públicas se relaciona às formas de exercício do poder e a capacidades diferenciais, por parte dos agentes, de influenciar o processo político. Assumindo explicitamente uma "visão radical" do poder (Lukes 2005), admite-se que perspectivas unidimensionais ou pluralistas centradas na capacidade de influência de um agente sobre outro e no conflito direto e observável, isto é, que caracterizam o exercício do poder predominantemente através da coerção, seriam claramente insuficientes para descrever o espectro da definição de agenda e do ciclo de políticas públicas como um todo.

Mais que isso, perspectivas bidimensionais, apoiadas no trabalho de Bachrach e Baratz (2011) avançam com um entendimento mais amplo do poder como capacidade de controle da agenda de políticas públicas e de bloqueio da agência de grupos de interesse desafiantes. Essas perspectivas são capazes de incorporar heuristicamente tanto os processos de tomada de decisão quanto aqueles de criação ou reforço de barreiras à emergência pública de conflitos políticos por meio de valores, crenças, instituições etc. que atuam consistentemente a favor e em detrimento de determinados agentes.

O trabalho de Lukes (2005) avança, ainda, uma perspectiva tridimensional que reconhece a diversidade dos modos de impedimento da entrada de questões 
na agenda de políticas públicas, incorporando o conflito latente como contradição de interesses entre tomadores de decisão e agentes excluídos do seu exercício, e fundado na possibilidade de não expressão e inconsciência dos interesses desses últimos. Nesse sentido, o exercício do poder remete à capacidade de "manter o público e grupos excluídos ignorantes dos problemas subjacentes, formulações alternativas de problemas ou opções para sua resolução" (Birkland 2007, p.68).

Nesse sentido, levando em consideração os elementos coercivos, restritivos da agência e, finalmente, inibidores de consciência em uma perspectiva relacional do poder no âmbito do ciclo de políticas públicas, o problema da mudança da agenda se torna um aspecto central da pesquisa sobre políticas públicas.

A opção pelo Modelo dos Fluxos Múltiplos (MFM) no entendimento da construção social da exploração petrolífera em territórios biologicamente e socialmente diversos no Equador, sua incorporação à agenda de políticas públicas em escala nacional e a elaboração e operacionalização de soluções em escala internacional diz respeito, portanto, à efetividade do modelo em incorporar uma perspectiva relacional da definição da agenda de políticas públicas. Desse modo, o MFM leva em conta a complexidade das interações entre restrições de ordem estrutural no âmbito do exercício do poder e as dinâmicas de influência dos grupos desfavorecidos na formulação e execução de políticas públicas, incluindo condições externas imprevistas, percepções sociais de problemas, mudanças político-eleitorais, estratégias de ação etc.

Levando em conta o fato de que a Iniciativa Yasuní-ITT não foi efetivamente implementada, e tendo seus processos de formulação e adoção tomado diversas formas, o enfoque analítico sobre os processos de reconhecimento do problema e de emergência de uma solução política por parte do Estado equatoriano é plenamente congruente com a adesão ao MFM e sua abordagem dos elementos de definição da agenda de políticas públicas.

É importante, ainda, distinguir o MFM em relação a abordagens incrementalistas de políticas públicas (Jann \& Wegrich 2007), considerando sua adequação a processos de mudança de ritmo e direção diante da excepcionalidade da Iniciativa Yasuní-ITT no rol das políticas de acesso a recursos naturais na América Latina.

Ademais, a referida opção pelo MFM merece ser avaliada em face da variedade de modelos de análise de políticas públicas que incorporam a definição de agenda no núcleo de suas preocupações teóricas, tais como o enfoque de Policy Communities e Issue Networks, a Teoria do Equilíbrio Pontuado e o Advocacy Coalition Framework, além das abordagens em termos de escolha racional que, por compartilhar pressupostos intencionalistas e racionalistas (McMaster 2009, pp.88-113), são consideradas pouco adequadas à abordagem aqui proposta.

II.2. Objetivos, origens e pressupostos

O MFM foi elaborado por Kingdon (1984) como uma proposta para explicar a definição da agenda de políticas públicas. Considerando as etapas do ciclo de políticas públicas, o modelo lidaria principalmente com as etapas de seleção dos problemas e escolha de alternativas, não incorporando questões associadas à implementação da política ou seu monitoramento (Pinto 2008).

A ideia de fluxos na definição de problemas em política pública não é uma proposta original de Kingdon (1984); ele se inspira, explicitamente, no Modelo da Lata de Lixo (MLL), proposto por Cohen, March e Olsen (1972). Este 
modelo, por sua vez, busca explicar a tomada de decisão em organizações caracterizadas como "anarquias organizadas". Estas seriam identificadas por apresentarem preferências problemáticas, tecnologias imprecisas e participantes fluidos (Bendor, Moe \& Shotts 2001).

Dadas essas características, Cohen, March e Olsen (1972) defendem que as decisões nestas organizações não teriam como ser compreendidas pelas intenções dos participantes ou por explicações racionais sobre o comportamento das organizações. Ao contrário, argumentam serem necessários novos modelos analíticos. Estes devem considerar outros elementos, uma vez que a tomada de decisão seria resultado de processos complexos e imprevisíveis. Assim, a tomada de decisão poderia ser vista como "uma lata de lixo na qual vários tipos de problemas e soluções são jogados por participantes na medida em que são gerados. A combinação de lixo em uma lata de lixo particular dependeria da mistura de latas disponíveis, das etiquetas presas às outras latas, do tipo de lixo produzido no momento, e da velocidade com que o lixo é coletado e removido" (Cohen, March \& Olsen 1972, p.2). Em outras palavras, eles descrevem a tomada de decisão como "uma coleção de escolhas procurando por problemas; questões e sentimentos procurando por situações nas quais podem ser renovados, soluções procurando por questões que podem responder, e tomadores de decisão procurando por trabalho" (Cohen, March \& Olsen 1972, p. 2). Embora os autores identifiquem que esses três fluxos (problemas, soluções e participantes) se influenciam mutuamente, eles argumentam que eles deveriam ser entendidos como independentes e exógenos ao sistema.

Com base no MLL, o MFM foi construído partindo-se do princípio de que a tomada de decisão nas organizações ocorre em contextos de ambiguidade. Zahariadis (2007) identifica ambiguidade em situações onde há diferentes formas de se pensar a respeito de um fenômeno. Sobre essa questão, Kingdon (1984) afirma que, muitas vezes, os tomadores de decisão não sabem como alcançar os objetivos propostos e Howlett e Ramesh (2003) explicam que, na perspectiva do MFM, as metas e os caminhos para alcançá-las não são definidos a priori, mas ao longo do processo político.

Dessa forma, segundo Zahariadis (2007), o modelo seria baseado em três pressupostos principais. Primeiramente, considera que a atenção individual é serial, ou seja, por questões cognitivas, as pessoas somente conseguem se concentrar em poucos assuntos por vez. Enquanto isso, o processamento é paralelo e as instituições burocráticas conseguem lidar com diferentes questões ao mesmo tempo. Em segundo lugar, os elaboradores de políticas tomam decisões em um contexto de restrição de tempo, onde não se pode buscar indefinidamente pela "melhor solução". Por fim, a tomada de decisão se baseia na junção de três fluxos (problemas, soluções e políticas) que evoluem de forma independente.

\section{II.3. Uma breve descrição}

Partindo dessas premissas, Kingdon (1984) construiu o MFM para tentar explicar o processo de definição de agenda no sistema legislativo federal dos EUA. Diferentemente da proposta de Cohen, March e Olsen (1972), Kingdon (1984) fez uma primeira divisão entre os participantes e o processo em si. Para esse autor, haveria nas organizações quatro fluxos independentes: problemas, soluções, oportunidades e participantes. Da mesma forma que no MLL, porém, os fluxos seriam independentes e teriam vida própria.

O primeiro fluxo seria composto pelos problemas. Vários mecanismos poderiam disparar situações que exigiriam a atenção dos tomadores de decisão. Entre eles estariam indicadores (sociais, econômicos e ambientais) gerados por 
instituições de pesquisa, eventos focais (desastres e crises) e feedback recebido pelos políticos de formas variadas (petições, notícias na mídia etc.) (Kingdon 1984; Pinto 2008).

Em segundo lugar, haveria um fluxo relacionado às políticas ou soluções para os problemas. Esse fluxo se daria a partir da acumulação de conhecimento por diferentes especialistas. Nesse sentido, ao contrário das perspectivas mais racionais, que afirmariam que as soluções seriam desenvolvidas para resolver problemas, Kingdon (1984, p.85) argumenta que "as pessoas gerariam e debateriam soluções pelo fato de terem um interesse individual (por exemplo, manter o emprego ou fortalecer sua instituição) não como tentativa de solucionar um problema ou na antecipação de uma decisão futura”. A construção das soluções é uma preocupação central no MFM, uma vez que o autor se propôs a discutir até que ponto a persuasão e a difusão de ideias poderiam superar a pressão e o jogo de poder político na tomada de decisão.

O terceiro fluxo diz respeito aos processos políticos inerentes à definição da agenda. Este fluxo trata do "humor nacional", da opinião pública, do resultado das eleições e de mudanças na administração de órgãos governamentais (Kingdon 1984).

O MFM assume que há momentos críticos em que dois ou três dos fluxos se encontram, abrindo, então, as “janelas de políticas públicas”. Em tais condições existiria a possibilidade de mudança ou implementação de uma opção política que, até então, não se mostrava plausível (Khayesi \& Amekudzi 2011). Nestas situações, os problemas são reconhecidos, as soluções são identificadas e o clima político é propício. Dependendo, principalmente, do fluxo político, as janelas podem se abrir de forma previsível ou imprevisível (Kingdon 1984).

Howlett e Ramesh (2003) alertam, porém, que embora a abertura das janelas de políticas públicas seja uma condição necessária, ela não é suficiente para a solução dos problemas. Segundo Kingdon (1984) as janelas não ficam abertas para sempre e, assim como elas se abrem, podem também se fechar em decorrência de diferentes processos. Primeiramente, os participantes podem ter a percepção de que o problema tenha sido solucionado, mesmo que isso não tenha ocorrido de fato. Em segundo lugar, os participantes podem ter dificuldade de implementar a ação, e assim desistir de investir esforços na questão. Além disso, os eventos que permitiram que as janelas fossem abertas podem passar ou a pessoa que iniciou o processo pode mudar de cargo. Por fim, a janela pode ainda se fechar pelo fato de nenhuma solução se mostrar viável.

Porém, o acoplamento dos fluxos e a abertura das janelas não ocorrem espontaneamente. Kingdon (1984) indica ser fundamental a ação dos agentes nesse sentido. Em sua estrutura, o autor divide os agentes entre aqueles que atuam no interior do governo (membros do Executivo, técnicos em cargos de confiança, burocratas e parlamentares) e os que estão fora do sistema (movimentos sociais, acadêmicos, mídia, partidos e opinião pública). Esses agentes atuariam de forma fluida, entrando e saindo de cena de acordo com a decisão tomada (Pinto 2008).

Dentre os agentes, existiria um grupo específico, os "empreendedores de políticas públicas", cuja função seria abrir as janelas políticas. Eles seriam agentes dispostos a investir tempo e energia em acoplar os diferentes fluxos (Pereira \& Teixeira 2011). Entre as habilidades destes empreendedores estariam: legitimidade sobre um assunto (derivada de suas especialidades, capacidade de falar em nome dos outros ou posição de poder), conexões políticas, capacidade de negociação e persistência (Kingdon 1984). 
II.4. Aplicações, potenciais e limitações

2 "O construcionismo social coloca as práticas profundamente enraizadas e a linguagem ou 'discurso' sobre ações do dia a dia no centro de qualquer análise de problemas socioambientais [...] Esta estratégia observa a forma como a sociedade age e interage com o ambiente como sendo condicionada pela forma pela qual ela percebe e problematiza aquele ambiente" (Redclift \& Woodgate 2010, p.316).
Desde sua proposta inicial, o MFM tem sido utilizado para analisar o processo de tomada de decisões políticas em países e setores variados. Em seu estudo original, Kingdon (1984) estudou as políticas federais de saúde e transporte nos EUA. Também nos EUA, Chen (2011) discutiu, a partir do MFM, a possibilidade da implementação de trens de alta-velocidade. Zahariadis e Allen (1995) utilizaram o modelo para descrever as políticas de privatização na Inglaterra e na Alemanha.

Também no Brasil, o modelo vem sendo usado para pesquisar políticas em diferentes setores. Por exemplo, Pereira e Teixeira (2011) o utilizaram para discutir a inclusão de catadores de materiais recicláveis em políticas locais e nacionais; Khayesi e Amekudzi (2011) estudaram como políticas locais foram propostas para reduzir a dependência de automóveis em Curitiba; Gottems et al. (2013) examinaram as contribuições e limites do MFM para avaliar políticas de saúde no âmbito do SUS; finalmente, Nagem e Silva (2013) utilizaram o modelo para explicar como o tema da economia solidária conseguiu espaço na agenda do governo, resultando na criação da Secretaria Nacional de Economia Solidária (SENAES).

A difusão da utilização do MFM se deve em parte à forma como o modelo aborda o processo de tomada de decisão. Howlett e Ramesh (2003) argumentam que modelos racionais e incrementais adotam como premissas a intencionalidade, a compreensão dos problemas pelos políticos e a previsibilidade dos efeitos das decisões. Dessa forma, tais modelos teriam pouca capacidade explicativa em situações que não apresentassem tais características. Ao mesmo tempo, Zahariadis (2007) critica os modelos baseados na perspectiva racional (escolha racional) e persuasão (construcionismo ${ }^{2}$ ) pelo fato deles incorporarem de forma superficial a discussão sobre manipulação política. Para o autor, a forma como o MFM aborda essas questões seria um diferencial importante no estudo de situações caracterizadas por ambiguidade.

Apesar da aceitação e das vantagens identificadas no MFM, ele, assim como o MLL, também recebeu diferentes críticas. Primeiramente, o modelo teria sido construído para situações onde a estrutura institucional fosse fragmentada e permeável, com uma participação fluida e pluralista, e ainda com coalizões temporárias. Em outras palavras, ele se adequaria bem ao sistema político dos EUA, mas não necessariamente apresentaria a mesma fecundidade explicativa em outros países (Mucciaroni 1992). Em segundo lugar, ambos os modelos seriam considerados muito situacionais, tendendo a supervalorizar a conjuntura como principal direcionador da tomada de decisão. Dentro dessa perspectiva, tanto o MLL quanto o MFM menosprezariam o papel das instituições e das estruturas políticas (Bendor et al., 2001; Sager \& Rielle 2013). Finalmente, como decorrência dessa perspectiva casuística, os modelos ainda receberiam críticas por terem um caráter extremamente descritivo e baixo poder preditivo, não permitindo identificar, por exemplo, quais tipos de problemas teriam maior probabilidade de ingressar na agenda de políticas públicas (Mucciaroni 1992, Gottems et al., 2013).

Além dessas críticas mais diretas, existem questões em aberto sobre a aplicação do MLL e do MFM. Por um lado, há autores que debatem até que ponto os fluxos propostos seriam efetivamente independentes. Para eles, existiria uma interdependência entre os diferentes fluxos, e alterações em um deles reforçariam mudanças em outros, aumentando a chance de acoplamentos e abertura das janelas de políticas públicas (Mucciaroni 1992; Bendor et al., 2001). Ao mesmo tempo, discute-se a abrangência dos modelos; embora o MFM tenha sido proposto por Kingdon (1984) para estudar a definição de 
agenda, há aqueles que propõem a aplicabilidade do modelo para explicar todo o processo de formulação da política (Zahariadis 2007).

Sendo assim, o MFM pode ser considerado como uma adaptação do MLL para tentar descrever e, na medida do possível, colaborar para o entendimento da tomada de decisão de organizações (políticas). Apesar de ser usado em diferentes contextos, ainda apresenta algumas limitações a serem superadas. Contudo, argumenta-se, neste trabalho, que o seu uso na análise da Iniciativa Yasuní-ITT contribui para salientar algumas particularidades desse processo, especialmente a possibilidade de combinar discursos de natureza moral e econômica (fluxo dos problemas), a importância dos contextos nacional e internacional no lançamento da campanha (fluxo político) e a oportunidade criada pela mobilidade de representantes de diferentes arenas, em particular, entre organizações sociais no governo (empreendedores de políticas públicas).

\section{A Iniciativa Yasuní-ITT}

A Iniciativa Yasuní-ITT (cf. Figura 1) corresponde a um projeto apresentado pelo governo do Equador à Assembleia Geral da Organização das Nações Unidas (ONU) em 2007, que consistia na opção de não explorar as reservas de petróleo correspondentes aos campos Ishpingo-TiputiniTambococha (ITT), no Parque Nacional de Yasuní (PNY), em troca de compensação econômica justificada pela não emissão de Gases de Efeito Estufa (GEE), preservação da biodiversidade e proteção aos direitos de povos indígenas. Suas origens remontam à proposta de uma moratória local, apresentada por organizações como a Nacionalidad Waorani del Ecuador (NAWE) e a Confederación de Nacionalidades Indígenas del Ecuador (CONAIE) como resposta à concessão de uma área de exploração à petroleira Maxus e à consequente instalação de infraestrutura de apoio na Reserva Étnica Waorani (REW) em 1992.

Ao longo desses 15 anos, o reconhecimento da questão da exploração petrolífera em áreas biodiversas e ocupadas por populações indígenas como um problema, a seleção da moratória como solução privilegiada por parte do governo equatoriano e sua posterior "retirada" da agenda de políticas públicas assumiram formas dependentes da interação de múltiplos agentes, em escalas nacional e internacional, que podem ser entendidos a partir do MFM. Nesse sentido, a análise dos fluxos de problemas, soluções e políticas relacionados à Iniciativa Yasuní-ITT demonstra a atuação ativa de diferentes agentes, mobilizando ideias e recursos estratégicos.

III.1. O papel dos agentes

III.1.1. A presidência
No Equador, a ênfase do MFM no protagonismo do presidente na definição da agenda se mostrou empiricamente adequada. Concentrando recursos institucionais, organizacionais e "de comando da atenção pública" (Capella 2007, p.32), Rafael Correa assumiu posição de centralidade na política de acesso aos recursos naturais já nas eleições presidenciais de 2006. Desde o início de seu mandato, a imagem ambientalista do governo equatoriano passou a ser amplamente divulgada devido às alterações na Constituição do país, bem como pela campanha internacional em torno da Iniciativa Yasuní-ITT. Nesse sentido, Correa foi parabenizado como "estrela da proposta" em diferentes fóruns internacionais, como a União de Nações Sul-Americanas, a Assembleia Geral das Nações Unidas e a Organização dos Países Exportadores de Petróleo (Martin 2011; Rival 2010). 
Figura 1 - Mapa com a localização da Iniciativa Yasuní-ITT no território equatoriano.

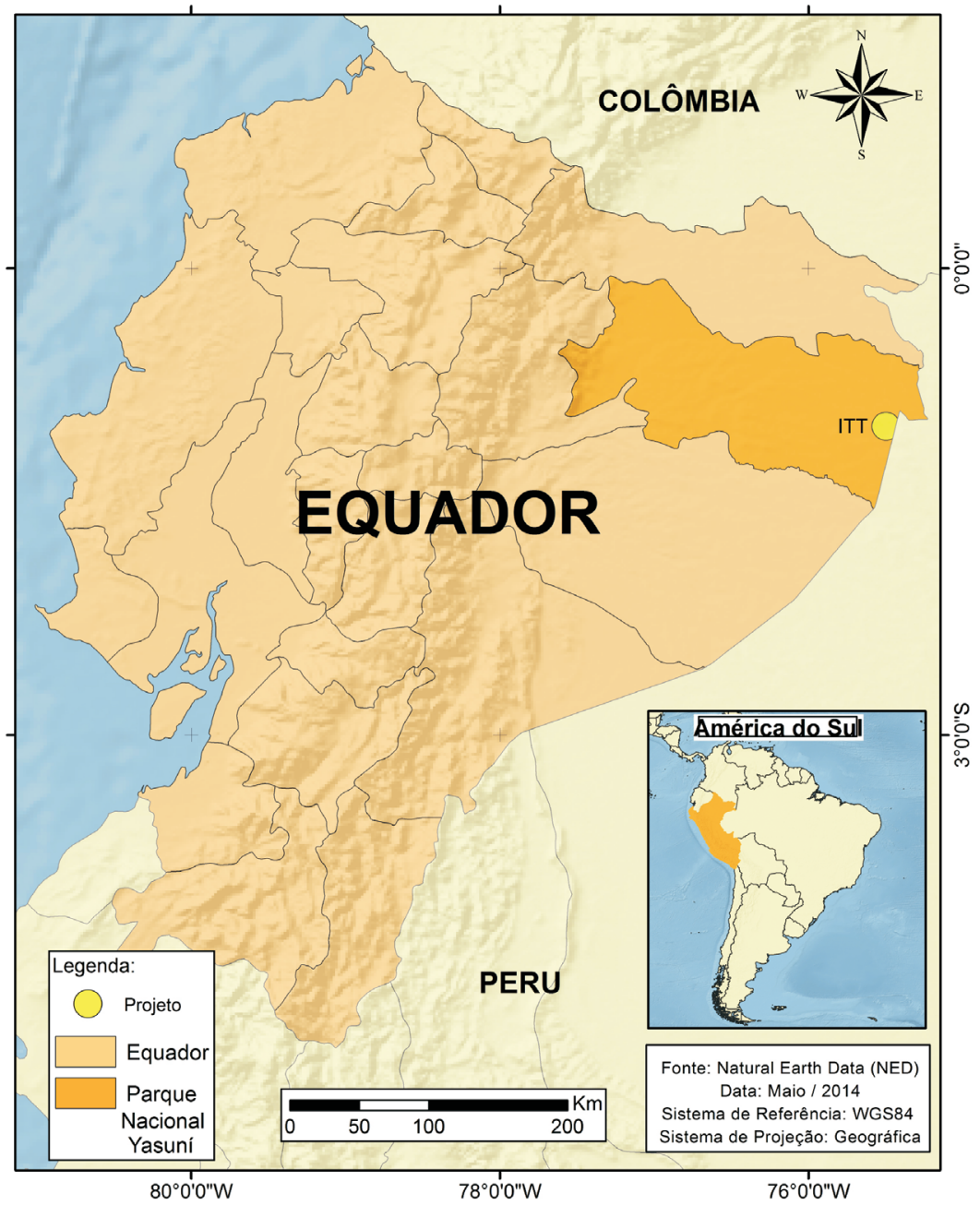

Fonte: Elaborado por Waltencir Menon Junior.

Apesar de propor a redução da dependência econômica das exportações de petróleo, o compromisso de Correa com a superação do modelo extrativista clássico deve ser considerado com ressalvas. De certa forma, sua estratégia pode ser avaliada como uma tentativa de compatibilizar algumas demandas de povos indígenas e organizações ambientalistas com uma orientação neoextrativista (Acosta 2011; Gudynas 2009; Milanez \& Santos 2013).

Há autores que argumentam que a disputa em torno da Iniciativa YasuníITT foi apenas uma estratégia retórica de combate a políticas neoliberais, uma vez que o governo manteve a extração de recursos naturais como principal estratégia para a obtenção de receitas. Sendo assim, o aumento de contratos e operações com indústrias mineradoras teria sido, ainda, uma importante estratégia da busca pelo aumento das receitas públicas (Arsel \& Angel 2012; Espinosa 2013).

Nesse sentido, Davidov (2012) argumenta que o Equador deixaria de ser um petro-Estado, cuja economia estaria nas mãos de transnacionais, para se tornar uma democracia populista com domínio estatal sobre seus recursos minerais. Assim, a disputa internacional com a indústria do petróleo daria a Correa capital político suficiente para expandir o setor extrativo mineral sem ser contestado. Essa perspectiva aparece explicitamente nas palavras de Correa quando este 
afirma que seria "um absurdo sentar sobre centenas de bilhões de dólares e dizer 'não' à mineração, por causa de romantismos, estórias, obsessões ou qualquer outra coisa" (Bebbington \& Bebbington 2010).

Sendo assim, de acordo com perspectivas mais críticas, a posição do governo nacional sobre Yasuní deve ser considerada, na melhor das hipóteses, ambígua. Na verdade, o governo não buscou resolver de fato as tensões entre a Petroecuador e o Comité Administrativo y Directivo (CAD), órgão criado para promover a Iniciativa Yasuní-ITT dentro do governo. Indo mais além, Martin (2011) menciona que, enquanto o governo nacional promovia a proposta no exterior, encaminhava domesticamente o processo de licenciamento da extração de petróleo nos campos ITT.

III.1.2. Empresas petroleiras

O Equador possui uma longa história de extração de petróleo, o que fez com que as empresas petroleiras tenham se tornado agentes importantes nas decisões políticas e econômicas do país. O início da extração de petróleo no Equador data de 1878, mas esta atividade só se intensificou a partir dos anos 1930; nesta década, várias empresas transnacionais se instalaram, primeiramente na região costeira e, em um segundo momento, na região amazônica. Conforme apresentado na Tabela 1, nesta região ela tem gerado elevado risco de degradação ambiental, em particular devido à proximidade de áreas protegidas, além de se colocar como um importante foco de conflito com comunidades indígenas, incluindo algumas em isolamento voluntário (Acosta 2009).

A atividade de transnacionais foi majoritária durante a maior parte do século XX, até que, na década de 1970, se instituiu a Corporación Estatal Petrolera Ecuatoriana (atual Petroecuador). A partir do final do século XX, a participação do Estado foi crescente; nos anos 2000, as estatais Petroecuador e Petroamazonas, além da Operaciones Rio Napo (joint venture entre Petroecuador e Petroleos de Venezuela), respondiam por $73 \%$ da produção petroleira (EIA 2014).

A extração excessiva levada a cabo por essas empresas, porém, gerou novos desafios para o Equador. Desde o início dos anos 2000, a quantidade de petróleo descoberto foi se reduzindo em quantidade e qualidade. A maior parte dos novos campos se encontrava em locais cada vez mais remotos na região amazônica, principalmente em áreas protegidas, como os parques nacionais Yasuní, Sangay, Sumaco-Napo-Galeras e Llanganates; as reservas biológicas de Cayambe-Coca e Limoncocha; e a Reserva Faunística Cuyabeno. Além disso, o petróleo desses campos era do tipo pesado e extrapesado, de menor preço no mercado, maior impacto ambiental e que exige um beneficiamento mais caro, devido à alta concentração de enxofre e de metais pesados (Acosta 2009; Martínez 2000).

Assim, a discussão sobre a possível moratória da extração de petróleo em Yasuní era emblemática para as empresas pois poderia criar jurisprudência que favorecesse a proibição da exploração em outras regiões. Embora a literatura não mencione explicitamente o envolvimento das transnacionais nas decisões sobre a Iniciativa Yasuní-ITT, a possibilidade de prejuízo para as empresas era grande. Por exemplo, o debate sobre a atividade da Petrobrás no Bloco 31, vizinho ao PNY, teve forte impacto na atividade da empresa no país (Leroy \& Malerba 2005). Todavia, de todas as empresas petrolíferas a mais ativa no debate foi a Petroecuador, negociando, por dentro das agências governamentais, a possibilidade de licenciamento da exploração do campo ITT (Espinosa 2013; Finer et al., 2009). 
Tabela 1 - Empresas que atuam na Amazônia Equatoriana (dados referentes a 2008)

\begin{tabular}{|c|c|c|c|c|}
\hline Empresa & Origem & Áreas protegidas & $\begin{array}{l}\text { Comunidades } \\
\text { tradicionais }\end{array}$ & Conflitos \\
\hline CGC & Argentina & & Kichwa & $\begin{array}{l}\text { Possíveis impactos } \\
\text { ambientais }\end{array}$ \\
\hline Tecpecuador & Argentina & $\begin{array}{l}\text { Reserva Ecológica Cofán } \\
\text { Bermejo }\end{array}$ & $\begin{array}{l}\text { A'i } \\
\text { Cofán, Shuar, mestiços }\end{array}$ & \\
\hline Ecuador TLC & Brasil & & Kichwa, mestiços & $\begin{array}{l}\text { Asfaltamento de } \\
\text { estrada, construção de } \\
\text { pontes e aterramento de } \\
\text { dutos }\end{array}$ \\
\hline Petrobrás & Brasil & $\begin{array}{l}\text { Parque Nacional } \\
\text { Yasuní, Zona Intangível } \\
\text { tagaeri-taromenani }\end{array}$ & $\begin{array}{l}\text { Waorani, povos em } \\
\text { isolamento voluntário }\end{array}$ & $\begin{array}{l}\text { Indenização (Bloco 18); } \\
\text { exigência de contratação } \\
\text { de pessoal local }\end{array}$ \\
\hline Petrobell & Canadá & & & $\begin{array}{l}\text { Compensações a } \\
\text { comunidades locais }\end{array}$ \\
\hline ENAP - SIPEC & Chile & & & \\
\hline CNPC & China & $\begin{array}{l}\text { Reserva Ecológica } \\
\text { Cayambe-Coca }\end{array}$ & Kichwa, mestiços & \\
\hline Petroriental & China & $\begin{array}{l}\text { Parque Nacional } \\
\text { Yasuní, Zona Intangível } \\
\text { tagaeri-taromenani }\end{array}$ & $\begin{array}{l}\text { Kichwa, Shuar, Waorani, } \\
\text { Mestiços, povos em } \\
\text { isolamento voluntário }\end{array}$ & $\begin{array}{l}\text { Indenização por } \\
\text { vazamentos; } \\
\text { asfaltamento, construção } \\
\text { de pontes e aterramento } \\
\text { de dutos. }\end{array}$ \\
\hline Andes Petroleum & China & & Mestiços & Asfaltamento de estrada \\
\hline Petroecuador & Equador & $\begin{array}{l}\text { Reserva Ecológica } \\
\text { Limoncocha, Reserva } \\
\text { Pañacocha, Parque } \\
\text { Nacional Yasuní, Reserva } \\
\text { Faunística } \\
\text { Cuyabeno, Zona } \\
\text { Intangível } \\
\text { tagaeri-taromenani }\end{array}$ & $\begin{array}{l}\text { Kichwa, Secoya, Shuar, } \\
\text { Siona, Waorani, mestiços, } \\
\text { povos em isolamento } \\
\text { voluntário }\end{array}$ & \\
\hline Tripetrol & Equador & & & \\
\hline Petrosud & Equador & & Shuar, Waorani, mestiços & $\begin{array}{l}\text { Idenização (Campo } \\
\text { Pindo) }\end{array}$ \\
\hline Repsol YPF & Espanha/ Argentina & Parque Nacional Yasuní & Waorani & \\
\hline $\begin{array}{l}\text { Burlington Re- } \\
\text { sources, Arco }\end{array}$ & EUA & & Kichwa & \\
\hline City Oriente & EUA & & Kichwa, mestiços & Asfaltamento de estrada \\
\hline Perenco & França & & Kichwa, mestiços & $\begin{array}{l}\text { Desrespeito a unidades de } \\
\text { conservação }\end{array}$ \\
\hline Agip Oil & Itália & & Kichwa, Shuar, Waorani & \\
\hline
\end{tabular}

Fonte: Os autores, a partir de Acosta (2009).

III.1.3. ONGs, movimentos sociais e especialistas

Em oposição aos interesses das empresas petroleiras, um conjunto diversificado de agentes desempenhou papeis importantes tanto na conformação da questão da exploração petrolífera em territórios biodiversos e habitados por povos tradicionais quanto na configuração da solução da moratória, inserindo a Iniciativa Yasuní-ITT na agenda de políticas públicas e modificando sua estrutura. 
As ONGs tiveram um papel muito relevante tanto na formulação quanto na divulgação nacional e internacional da proposta. Durante a elaboração da Iniciativa, a organização Acción Ecológica secretariava a Oilwatch, uma rede de resistência a atividades petrolíferas em países tropicais. A Acción Ecológica foi uma das responsáveis pela concepção e formalização da Iniciativa, e sua posição dentro da Oilwatch contribuiu para facilitar a difusão internacional da proposta (Arsel \& Angel 2012; Espinosa 2013).

Nesse sentido, a formação de uma rede de apoio à Iniciativa, envolvendo Organizações Não Governamentais (ONGs) ambientalistas, movimentos campesinos, movimentos urbanos, grupos indígenas, entre outros, foi de extrema importância. O intercâmbio com ONGs internacionais, como Amazon Watch e Sierra Club Legal Defense Fund, e a participação em edições do Fórum Social Mundial, também contribuíram para internacionalizar a proposta (Espinosa 2013; Martin 2011). Ao mesmo tempo, o envolvimento de ONGs estrangeiras também pode ter contribuído para a inclusão de novas pautas e demandas não necessariamente prioritárias para os movimentos sociais equatorianos, como, por exemplo, a questão da contribuição do petróleo para as mudanças climáticas globais.

Ao mesmo tempo, tiveram papel essencial as entidades indígenas. Em 1990, jovens lideranças Waorani criaram a Organización de la Nacionalidad Huaorani de la Amazonia Ecuatoriana (ONHAE), posteriormente renomeada Nacionalidad Waorani del Ecuador (NAWE). Em 2005, foi também criada a Associación de Mujeres Waorani de la Amazonia Ecuatoriana (AMWAE). A NAWE, posteriormente, integrou tanto a Confederación de Nacionalidades Indigenas de la Amazonia Ecuatoriana (CONFENIAE) quanto a Confederación de Nacionalidades Indígenas del Ecuador (CONAIE). Embora pudesse articular as demandas das comunidades Waorani, recebendo apoio de outras organizações indigenistas que também lutavam pela defesa de seus territórios (Espinosa 2013; Finer et al., 2009), a NAWE seria uma "associação relativamente fraca", pressionada pela sobreposição de áreas concedidas à exploração de petróleo a seu território (Reed 2011, p.540).

Por sua vez, um grupo de cerca de 50 especialistas, que partilhavam preocupações acerca da preservação da biodiversidade do PNY em face da proposta de construção de uma rodovia em sua área, deu origem ao Scientists Concerned for Yasuní em 2004. O grupo promoveu a sistematização de resultados de pesquisa de múltiplas fontes e buscou acessar esferas institucionais relevantes por meio de comunicação direta com o governo, promovendo ideias conservacionistas em círculos governamentais e influenciando a opinião pública. Bellettini e Ordóñez (2011) interpretam seu papel a partir da noção de comunidade epistêmica, reconhecendo, no entanto, os limites fluidos entre intelectuais, pesquisadores, ativistas e o próprio partido governante, Alianza País.

Por sua vez, alguns indivíduos oriundos destes grupos e organizações assumiram papeis relevantes na formulação, divulgação e legitimação da Iniciativa Yasuní-ITT, sendo identificados como empreendedores de políticas públicas no MFM. Dotados de legitimidade apoiada em expertises variadas, conexões políticas, habilidades de negociação, além de persistência (Capella 2010), alguns desses empreendedores tornaram-se membros do governo Correa, ocupando espaços institucionais centrais e construindo uma imagem nacional e internacional que facilitou a promoção da Iniciativa. Exemplos desses indivíduos incluem Alberto Acosta que, depois de ter trabalhado no setor petrolífero, ocupou o Ministerio de Energía y Minas (MEM) e foi Presidente da Asamblea Constituyente; e Maria Fernanda Espinoza, que foi diretora da International Union for Conservation of Nature (IUCN) e, posteriormente, ocupou o 
Ministerio de Relaciones Exteriores y Movilidad Humana (Arsel \& Angel 2012; Bebbington \& Bebbington 2010; Martin 2011; Rival 2010).

Nesse sentido, a despeito das diferenças significativas nas ideias e valores mobilizados pelas organizações da sociedade civil e cientistas, comunidades indígenas e seus organismos de representação política, e empreendedores de políticas públicas, suas relações próximas, trânsito fluído entre os setores governamental e não governamental e preocupações partilhadas quanto à expansão da exploração petrolífera na Amazônia equatoriana permitiram forjar propriamente uma comunidade de política (Capella 2007), particularmente influente no que respeita à formulação e suporte da alternativa da moratória.

III.1.4. Instituições internacionais

A Iniciativa Yasuní-ITT foi apoiada por instituições internacionais, que tanto pressionaram o governo equatoriano a tomar medidas com relação aos grupos isolados, como também agiram como promotores e legitimadores da proposta no cenário internacional.

Já em 2007, a Comissão Interamericana de Direitos Humanos, motivada por movimentos equatorianos, apresentou uma solicitação ao governo do Equador para que adotasse medidas que protegessem a integridade dos Tagaeri e Taromenane. Essa iniciativa fez com que o governo nacional criasse um plano de medidas, que envolvia a criação de pontos de controle policiais e uma maior presença do Estado na região (Finer et al., 2009).

Ainda no âmbito das instituições multilaterais, a Convenção-Quadro das Nações Unidas sobre Mudança do Clima (UNFCCC) e a Convenção n 169 da Organização Internacional do Trabalho sobre Povos Indígenas e Tribais também foram importantes elementos de legitimação da Iniciativa. Da perspectiva das mudanças climáticas, o debate sobre responsabilidades comuns, porém diferenciadas, bem como a argumentação a respeito da mudança de modelo energético do Equador, foram importantes estratégias de divulgação da proposta. Da mesma forma, as possibilidades criadas pela proposta para proteção dos povos isolados também receberam bastante apoio dentro do contexto da Convenção nº 169 (Espinosa 2013).

Outro elemento internacional que aumentou a visibilidade da proposta foi o apoio operacional e financeiro dado pela Organização das Nações Unidas (ONU) e por países europeus. Nesse sentido a Assembleia Geral da ONU propôs um convênio para supervisionar um fundo internacional que recebesse os recursos destinados à Iniciativa Yasuní-ITT (Larrea 2010; Espinosa 2013).

III.2. Os fluxos múltiplos

III.2.1. O fluxo dos problemas

Para compreender a importância dos campos ITT, bem como do PNY, para o Equador, é necessário descrever a forma como o setor petrolífero se implantou no país e a relação que criou com a economia e a sociedade. O Equador possui reservas de petróleo comprovadas de 8,24 bilhões de barris de petróleo, o que o coloca na $19^{\mathrm{a}}$ posição em termos de reservas mundiais. A economia do país apresenta forte relação com o setor; por exemplo, em 2012, a renda do petróleo correspondeu a 19,1\% do PIB do Equador, participação próxima às da Nigéria $(26,8 \%)$ e da Venezuela (26,7\%) (World Bank 2013). A importância do petróleo pode ser percebida na economia como um todo, mas com primordial relevância para a balança comercial do país. As exportações de petróleo representam mais de $30 \%$ do PIB, sendo o $11^{\circ}$ fornecedor dos EUA (Martin 2011). 
Assim, o desempenho econômico do Equador muito se confunde com a história da atividade petroleira. Ao longo da primeira metade do século XX, os produtos agrícolas figuravam como os principais produtos exportados. Essa situação foi alterada a partir da década de 1970, quando a intensificação da exploração e o aumento do preço do petróleo no mercado internacional promoveram um período de elevado crescimento econômico, conforme apresentado na Tabela 2.

Este período de "bonança" petroleira permitiu um aumento considerável no consumo doméstico do Equador, porém não garantiu um aprimoramento da capacidade produtiva do país, levando a um aumento constante da importação de manufaturados, do endividamento internacional e da exportação do petróleo. Ao longo dos anos 1980, todavia, houve uma brusca queda no preço do petróleo, que passou de US\$ 36/barril (1980) para US\$ 18/barril (1989), acarretando uma inversão no fluxo de capitais (World Bank 2014).

Com a redução dos preços do petróleo, o Equador aprofundou seu endividamento internacional e o governo iniciou um longo processo de negociação com credores internacionais. Como parte destas negociações, o país passou a incorporar diferentes condicionantes impostas pelo Fundo Monetário Internacional (FMI) e pelo Banco Mundial, principalmente relacionadas à privatização das empresas estatais e à abertura comercial. Estas negociações, porém, não impediram a drenagem da renda petroleira para o exterior; por exemplo, em 1986, toda a receita de exportação do país foi transferida para os credores internacionais (Acosta 2009; Davidov 2012).

Ao longo dos anos 1990, continuou o aprofundamento do modelo neoliberal. Pressões de grupos internos e de instituições externas levaram à modificação da política de comércio exterior equatoriana, ampliando a abertura, assim como induziram a redução do tamanho do Estado. Neste período foram aprovadas a Ley de Mercado de Valores, a Ley de Modernización del Estado e a Ley General de Instituciones del Sistema Financiero. Estas mudanças institucionais culminaram na quebra do sistema financeiro equatoriano, na moratória da dívida externa e na adoção do dólar como moeda oficial em 2000 (Acosta 2000; Davidov 2012).

A trajetória errática da economia equatoriana e seus impactos políticos dramáticos vêm sendo, desde pelo menos os anos 2000, interpretados criticamente a partir da dependência do país das receitas petrolíferas. Em particular, a dívida pública tornou-se um símbolo dos efeitos econômicos da exploração intensiva de petróleo, por meio da vinculação entre empréstimos internacionais a "pacotes econômicos de ajuste estrutural" (Larrea, Vásconez \& Greene 2008, p.3) e, principalmente, da "dominação e controle político e econômico"

Tabela 2 - Indicadores econômicos

\begin{tabular}{|c|c|c|c|c|c|}
\hline Indicador & 1971 & 1981 & 1990 & 2000 & 2010 \\
\hline PIB (US\$ milhões correntes) & 1.602 & 13.946 & 15.239 & 18.327 & 69.555 \\
\hline Exportações (US\$ milhões correntes) & 199 & 2.568 & $\mathrm{n} / \mathrm{d}$ & $\mathrm{n} / \mathrm{d}$ & 19.609 \\
\hline $\begin{array}{l}\text { Reserva monetária internacional } \\
\text { (US\$ milhões correntes) }\end{array}$ & 55 & 563 & $\mathrm{n} / \mathrm{d}$ & $\mathrm{n} / \mathrm{d}$ & $\mathrm{n} / \mathrm{d}$ \\
\hline Dívida externa (US\$ milhões correntes) & 261 & 5.870 & 12.172 & 13.337 & 14.962 \\
\hline Dívida externa (\% PIB) & $16 \%$ & $42 \%$ & $80 \%$ & $73 \%$ & $21 \%$ \\
\hline Juros da dívida (\% das exportações) & $15 \%$ & $71 \%$ & $\mathrm{n} / \mathrm{d}$ & $31 \%$ & $9 \%$ \\
\hline
\end{tabular}

N/d: Não disponível.

Fontes: Os autores, a partir de Acosta (2009) e World Bank (2013). 
externos, sendo representada pela campanha Amazonia por la Vida e pelo Grupo Nacional Contra la Deuda de Ecuador como essencialmente "ilegítima" (Amazonia por la Vida \& Grupo Nacional Contra la Deuda de Ecuador 2009). O endividamento econômico se ampliaria metaforicamente, convergindo para a "reinvidicação social das dívidas histórica, social, de gênero, ecológica e climática, esta última pela apropriação ilegítima e desproporcional da atmosfera e da capacidade de absorção de carbono do planeta" (idem).

O crescente endividamento levou o Equador a intensificar ainda mais a exportação de petróleo como estratégia para obtenção de divisas, duplamente como causa e consequência do aprofundamento do "modelo depredador" (idem). Neste sentido, foi estratégica a instalação do Oleoducto de Crudos Pesados, construído por um consórcio de empresas transnacionais para facilitar a exportação do petróleo da região amazônica. Esta expansão para o interior marcou o início de uma nova etapa da extração petroleira, não apenas pela abertura de novos e importantes campos, mas também pela ocupação de áreas frágeis, tanto do ponto de vista social, quanto do ambiental (Acosta 2000; Larrea 2010; Rival 2010).

Sendo assim, a ocupação da Amazônia equatoriana por empresas petrolíferas foi marcada por eventos de intensa degradação ambiental, bem como de conflitos com povos indígenas. Como consequência, a implantação das petroleiras ficou associada tanto à contaminação ambiental quanto ao desrespeito aos direitos das comunidades tradicionais.

Talvez o caso de conflito socioambiental decorrente de atividades petrolíferas mais emblemático tenha sido o causado pelas operações da Chevron Texaco. A empresa atuou na região entre os anos 1964 e 1992. Durante esse período perfurou mais de 300 poços de petróleo e despejou, no solo e em corpos d'água, 19 bilhões de barris de efluentes sem tratamento, incluindo água de produção. Este contaminante possui em sua composição benzeno, tolueno, etileno, naftaleno, fenóis, cádmio, chumbo, entre outros (Motta et al., 2013).

As operações da Chevron Texaco impactaram mais de 30 mil pessoas, incluindo colonos e indígenas. Esses impactos incluíram não apenas o deslocamento compulsório, a contaminação da água e intoxicação, como também foram associados ao aumento da taxa de incidência de câncer (31\% na região, contra $12 \%$ da média nacional). Além disso, às atividades da empresa foram associadas à extinção de povos indígenas como Tetetes e Sansahuaris e danos econômicos e culturais aos Siona, Secoya, Cofán, Kichwa e Waorani.

Como desdobramento dos conflitos, em 1993, comunidades impactadas iniciaram uma campanha internacional contra a Chevron Texaco e entraram com uma ação judicial na corte de Nova York, demandando indenização pelos danos causados. A corte decidiu transferir o julgamento para o Equador, onde a Corte Nacional de Justiça, em 2011, condenou a empresa a pagar uma indenização de US\$ 9,5 bilhões. Porém, a decisão foi anulada por um juiz dos EUA, em 2014, o que levou à intensificação da campanha internacional e a ações judiciais contra a empresa na Argentina, Brasil e Canadá (Acosta 2009; Martin 2011; BBC 2014).

Eventos de contaminação ambiental de grande porte, como o da Chevron Texaco, considerado "a pior catástrofe mundial relacionada ao petróleo" (Donziger 2004, p.1), apresentam o potencial de concentrar a atenção da opinião pública e de autoridades governamentais em uma questão, demandando soluções. Entretanto, é o engajamento dos agentes em sua construção social como problema (Capella 2007) que converte o episódio descontínuo em evento focalizador, como na ideia de um Chernobyl de la Amazonia veiculada por grupos afetados locais e empreendedores de políticas públicas para diferentes 
audiências, no Equador e internacionalmente (Donziger 2004). Imagens socialmente penetrantes e expressivas como esta foram recuperadas e enquadradas como horizonte de toda exploração petrolífera, e dos campos Yasuní-ITT em especial, representado com um "outro Chernobyl da Amazônia" inclusive por articulistas de mídia impressa (Guerrero 2011).

A ocupação da região do PNY não foi muito diferente dessa experiência. Em 1940, a Shell tentou instalar operações de extração em terras dos Waorani, tendo sido obrigada, no entanto, a abandonar o projeto após uma série de ataques de indígenas. Ao longo dos anos 1950, o governo equatoriano criou um protetorado para receber esses indígenas e liberar suas áreas para as empresas de petróleo. Entretanto, os Waorani não se adaptaram e, nos anos 1970, retornaram às suas terras originais. Em 1979, o governo criou, então, o PNY. O principal objetivo do parque é proteger uma das zonas de maior biodiversidade do mundo. Do ponto de vista da diversidade animal, já foram identificadas 165 espécies de mamíferos, 593 de aves, 150 de anfíbios, 121 de répteis e mais de 100 mil espécies de insetos por hectare. A estes números, somam-se cerca de 2.500 espécies de árvores e arbustos (Acosta et al., 2009; Finer et al., 2009; Larrea 2010). A importância social e ambiental da região fez com que a UNESCO, em 1989, integrasse o PNY à Reserva da Biosfera Yasuní (RBY), com uma área total de 982 mil hectares (Finer et al., 2009; Martin 2011).

Para escapar à pressão de grupos não indígenas, os Waorani haviam se aprofundado no interior do PNY e sobrevivido a partir da caça, coleta e agricultura itinerante (Acosta et al., 2009). Em 1990, o governo equatoriano decidiu criar a REW, que incluía não apenas parte da área do PNY, como também territórios que integravam anteriormente o protetorado. Outros grupos, como os Tagaeri e Taromenane, optaram, então, por viver em isolamento voluntário dentro da REW (Finer et al., 2009) e nas regiões mais remotas do PNY.

Apesar de todo o processo de zoneamento, as comunidades e ecossistema da região ainda continuaram sob ameaça. Por exemplo, em 1990, os limites ao norte do Parque foram modificados para permitir a extração de petróleo, reduzindo sua extensão. Apesar de a área total ter sido recuperada em posterior alteração, a modificação de limites continuou sendo um risco potencial. Ao mesmo tempo, a gestão do PNY continuava sofrendo problemas estruturais, uma vez que muitas das medidas de proteção não eram efetivadas. De certa forma, isso estaria associado às incertezas jurídicas decorrentes da constante pressão das indústrias petrolíferas pela oportunidade de explorar os recursos energéticos da região (Acosta et al., 2009; Finer et al., 2009).

Em 1999, o então presidente Jamil Mahuad estabeleceu, por meio de decreto, a Zona Intangible de Conservación. Esse decreto foi justificado, de forma geral, pela importância cultural e ecológica da região. Assim, ficavam proibidas atividades de extração de madeira e colonização. Essa proteção, embora importante, mostrou-se vulnerável, uma vez que poderia ser legalmente modificada ou mesmo anulada, por outro decreto ou por uma lei (Martínez 2000; Melo, Figueroa \& Wray 2009).

Entretanto, a criação das áreas protegidas não foi suficiente para assegurar a integridade dessas comunidades. Por exemplo, em 2003 houve o massacre de 15 Taromenane, o que forçou o envolvimento da Corte Interamericana de Direitos Humanos que, por sua vez, exigiu que o governo equatoriano garantisse proteção a esses grupos (Espinosa 2013).

Assim, as disputas sobre o território do PNY se polarizaram entre a extração de suas grandes reservas petrolíferas, a preservação de sua importante biodiversidade e o respeito aos povos tradicionais que lá se encontravam. Mais do 
que isso, o fluxo dos problemas relativos à Iniciativa Yasuní-ITT ia além do debate local e passava por questões nacionais, tais como balança comercial, dívida externa, dependência econômica e direitos humanos. Apesar de ter havido uma moldagem da identidade do país em torno da exploração petroleira (Acosta $e t$ al., 2009), existiria no Equador a identificação do setor com o processo de endividamento internacional, com o período neoliberal e com a reestruturação econômica (Davidov 2012). Além disso, a sociedade criou o entendimento de que o Equador havia perdido um importante recurso não renovável, sem promover seu desenvolvimento (Larrea 2010). Como consequência desse processo, os equatorianos desenvolveram um sentimento muito particular em relação ao petróleo; por um lado, existiria uma real dependência do país com relação à exportação do petróleo; por outro lado, a sociedade, de forma geral, entenderia que essa estratégia de desenvolvimento não promoveria as mudanças sociais e econômicas prometidas no nível nacional, muito menos no nível local (Rival 2010).

III.2.2. O fluxo das soluções

A primeira lei para tratar exclusivamente da exploração de petróleo já definia a propriedade estatal dos recursos petrolíferos; a partir desse arcabouço, as alterações posteriores buscaram definir, principalmente, a forma como se daria a relação entre Estado e empresas privadas. Em linhas gerais, durante a maior parte do século XX, houve pouca regulamentação e as empresas privadas tiveram bastante liberdade de ação. Houve uma primeira experiência de aumento do controle estatal nos anos 1970 que foi neutralizada pela guinada neoliberal dos anos 1990. Então, no final dos anos 2000, houve uma nova tentativa de fortalecimento do Estado e de apropriação pública da renda petrolífera (Acosta 2009; Melo et al., 2009).

O marco regulatório do petróleo sempre foi focado nas formas de contratos e tributação. Entretanto, a partir 2008, com a mudança da Constituição, ele passou a ser aplicado dentro de um novo contexto, que teve impactos diretos na forma como a sociedade se relacionava com as atividades extrativas minerais. A nova Constituição do Equador trouxe diferentes inovações legais do ponto de vista socioambiental, como a definição do Equador como Estado plurinacional, o reconhecimento dos direitos da natureza e a promoção do estado de bem viver (sumak kawsay). Em seu capítulo sétimo, a Constituição equatoriana, define da seguinte forma os direitos da natureza:

Art. 71: A natureza, ou Pacha Mama, de onde se reproduz e se realiza a vida tem direito a que se respeite integralmente sua existência e a manutenção e regeneração de seus ciclos vitais, estrutura, funções e processos evolutivos.

$[\ldots]$

Art. 72: A natureza tem direito à restauração. Esta restauração será independente da obrigação que têm o Estado e as pessoas físicas ou jurídicas de indenizar aos indivíduos e coletivos que dependam dos sistemas naturais afetados (República del Ecuador 2008).

Nesse contexto, a Constituição do Equador incorporou a percepção de que os direitos da natureza são intrínsecos a ela e não dependem de seu uso ou do grupo que ocupa determinado território. Em outras palavras, compensar as pessoas que foram prejudicadas pela degradação ambiental não seria suficiente para garantir os direitos da natureza.

Outra particularidade diz respeito ao princípio do "bem viver". A Constituição propõe que se busque desenvolver as potencialidades e capacidades humanas e que se garanta uma condição de vida digna às pessoas. Ao mesmo 
tempo, ela defende que se considere o respeito à natureza e que se conserve a biodiversidade (Melo et al., 2009; República del Ecuador 2008).

Apesar desses avanços, existem ainda questões contraditórias. Por exemplo, enquanto se proíbe a extração de recursos naturais não renováveis em áreas protegidas e zonas intangíveis, há a possibilidade de tal proibição ser anulada no caso de pedido do Presidente da República e de declaração de interesse nacional pela Assembleia Nacional (República del Ecuador 2008, art. 407). Sendo assim, a Constituição não se apresenta como um documento definitivo, deixando brechas para decisões discricionárias em contextos específicos.

Dessa forma, a construção da Iniciativa Yasuní-ITT teve como com base um marco regulatório ambíguo. Por um lado, a legislação setorial petrolífera se voltava principalmente para a relação Estado-empresas, sem ponderar ou considerar aspectos ambientais. Por outro lado, a Constituição oferecia um arcabouço legal suficientemente forte para embasar o projeto (Melo et al., 2009). Esse posicionamento dúbio teve impactos tanto no desenvolvimento do fluxo das soluções, quanto no fluxo político.

Desse modo, embora a inflexão na ação estatal em favor de maior controle dos recursos petrolíferos e da incorporação de reivindicações de direito por parte de grupos e organizações ambientalistas e indígenas resulte da competição entre alternativas em comunidades políticas específicas (Capella 2007), levando Alianza País e Rafael Correa ao poder em 2006, este esforço transcende o escopo do artigo. Diante da conjuntura de mudança difusa na agenda de políticas públicas equatoriana, por exemplo, a introdução e reconfiguração de políticas públicas de economia popular e solidária e de educação (cf. Ordoñez 2013), toma-se esta configuração institucional renovada, entretanto, como uma oportunidade de mudança na política de acesso aos recursos minerais, sendo possível destacar o papel de uma comunidade de política diversificada e ativa.

Nesse sentido, uma comunidade epistêmica organizada em torno do valor da biodiversidade passou a produzir e sistematizar evidências acerca da excepcionalidade de vida animal e vegetal da região, interpretando-as a partir de um enquadramento tipicamente conservacionista (Bellettini \& Ordoñez 2013, p.20) e representando o PNY em termos de singularidade, como "um dos refúgios de biodiversidade do Pleistoceno" (UICN e CEC 2010, p.4). Nesse sentido, o Scientists Concerned for Yasuní atribuiu funções protetivas únicas ao PNY, "protege[ndo] uma região de valor extraordinário em termos de sua biodiversidade, herança cultural e natureza selvagem em grande medida intacta" (Bellettini \& Ordoñez 2013, p.20).

A despeito do valor central da conservação para o subgrupo de especialistas, eram amplas as dimensões da comunidade de políticas em torno da Iniciativa, assim como fluidos os seus limites, de modo que a origem da solução da moratória pode ser traçada até a proposta de se "deixar o petróleo no subsolo", feita em 1992 pelas organizações indígenas NAWE e CONAIE em nome das comunidades Waorani. Essa proposta foi formulada como reação à abertura de uma estrada por parte da petroleira Maxus para a exploração do bloco 16 na REW (Espinosa 2013), mas não foi levada adiante. Naquele momento, os valores centrais do conflito enfocavam os direitos territoriais das populações indígenas. Posteriormente, o intercâmbio com ONGs ambientalistas nesta comunidade ampliada permitiu a "dilatação" do enquadramento de suas demandas, incluindo a perspectiva de preservação da biodiversidade. A partir desse momento, organizações como a NAWE e a CONAIE passaram a argumentar que, ao defender suas terras e direitos, estavam "protegendo o meio ambiente para o bem dos Equatorianos e do mundo" (Espinosa 2013, p.4). 
Em junho de 2006, a Iniciativa foi reapresentada ao então Presidente da República Alfredo Palacio e, principalmente, por uma comunidade de políticas que incluía indivíduos e organizações ambientalistas, como Manuel Pallares e Acción Ecológica; redes transnacionais de resistência à indústria petroleira, como Oilwatch; especialistas em Geologia, Engenharia de Petróleo, Antropologia, Direito, Economia etc., além de grupos de defensores dos direitos humanos, camponeses e organizações urbanas, dentre outros. Sua construção argumentativa cuidadosa combinava "argumentos sobre os direitos dos povos indígenas, sobre a conservação" a justificativas econômicas e "posicionamentos de especialistas" na área, relacionados à viabilidade técnica e econômica" (Llacta 2006).

As próprias organizações ambientalistas e seus mecanismos de influência sobre a opinião pública adaptavam-se diante da emergência da Iniciativa como solução política privilegiada, de maneira que a campanha Amazonía por la Vida, criada em 1989, "se reorganizou para promover ações em defesa de Yasuní” (Amazonía por la Vida 2015).

Nesta nova proposta, a Iniciativa Yasuní-ITT seria a "solução" para três "problemas". Além das questões associadas à proteção dos povos isolados e da biodiversidade da região, que já vinham sendo historicamente discutidas, outro elemento que fortaleceu a ideia da moratória do petróleo foi o debate que se estabeleceu em torno das estratégias de mitigação das mudanças climáticas (Acosta 2014). Com relação à emissão de GEE, por um lado, haveria um importante desincentivo ao desmatamento, evitando a emissão referente à biomassa da floresta; por outro lado, o não consumo do petróleo dos campos ITT significaria a não emissão de mais de 400 milhões de toneladas de carbono (Acosta et al., 2009). A associação da Iniciativa à mitigação de emissão de GEE foi muito forte pelo fato de o Equador ser altamente vulnerável às mudanças do clima, principalmente devido ao abastecimento de algumas de suas principais cidades depender do degelo de glaciares andinos. Ao mesmo tempo, a possibilidade de savanização da Amazônia ofereceria riscos à economia e ao equilíbrio ecológico do país (Larrea 2010).

A vinculação da questão climática e, consequentemente, a possibilidade da compensação econômica, constituíram alguns dos principais motivadores do envolvimento do governo. De certa forma, era esperado repetir as experiências dos anos 1980, quando o Equador fez uma série de transações de dívida por ambiente (debt for nature swaps) com o World Wildlife Fund, a The Nature Conservancy, e o Missouri Botanical Garden. Naquele momento, essas instituições pagaram parte da dívida externa do país que, em troca, utilizou o dinheiro para melhorar seus planos de gestão ambiental e a estrutura dos parques nacionais (Davidov 2012).

Mais importante, a permeabilidade entre a comunidade de políticas constituída em torno da Iniciativa e o governo tornou-se um elemento distintivo da mudança da agenda de políticas públicas acerca dos recursos minerais no Equador. Em adição às dimensões estratégicas do conhecimento especializado e do enfoque conservacionista constitutivas da proposta, o ingresso no governo de alguns proponentes dotados de características de empreendedores de políticas (Capella 2010), tais como Alberto Acosta e Maria Fernanda Espinoza, pode tanto ser visto como uma estratégia de influência direta (Bellettini \& Ordóñez 2011) por parte da comunidade de políticas, quanto uma medida de consensualidade atingida pela solução.

Entretanto, ao adotar a Iniciativa como política pública, a proposta ganharia novos contornos, de modo que o governo incluiu a exigência do pagamento de compensação pelos países industrializados, justificada pela contribuição do Equador para a mitigação das mudanças climáticas e pela necessidade de se 
obterem recursos para programas de desenvolvimento. Dessa forma, o governo equatoriano demandou o pagamento de cerca de US\$ 350 milhões por ano, durante dez anos, valor estimado como metade da receita que o país obteria se explorasse o petróleo. Esses recursos seriam utilizados pelo país, principalmente, em projetos para o desenvolvimento de energias de baixo carbono (Oilwatch 2007).

Sendo assim, ao longo da história do Equador, o debate sobre exploração de petróleo na Amazônia passou por diferentes momentos. Inicialmente ela foi vista como oportunidade econômica; posteriormente, devido aos diferentes graus de impactos ambientais e sociais, a atividade passou a ser questionada, sendo considerada, por alguns, como inadequada. Essa ideia levou à proposição da moratória da extração de petróleo, sem muita repercussão, nos anos 1990 e com maior aceitação nos anos 2000. Para essa mudança de perspectiva foi fundamental o contexto criado pela nova Constituição e sua representação como uma atividade de mitigação das mudanças climáticas. O papel da comunidade de políticas ampliada construída em torno da Iniciativa foi, entretanto, decisivo para a conversão da questão em um problema e para a convergência em torno da moratória como solução. Sua transformação em iniciativa governamental constitui uma medida da efetividade de suas ações. Finalmente, a conjuntura política na qual a emerge essa solução merece a atenção da próxima seção.

III.2.3. O fluxo da política
Um elemento fundamental que ajuda a entender a incorporação da Iniciativa Yasuní-ITT à agenda do governo diz respeito ao momento político pelo qual passava o Equador. No contexto interno, houve a eleição de Rafael Correa a partir de uma plataforma política que questionava o poder do setor petroleiro; ao mesmo tempo, no cenário internacional havia uma crescente discussão sobre políticas de mitigação das mudanças climáticas.

A partir do final dos anos 1990, começou a se formar no Equador a percepção de que os compromissos assumidos durante o período neoliberal comprometiam a renda petroleira sem garantir uma melhora da qualidade de vida da população, que continuava a sofrer com problemas associados à pobreza. Dessa forma, os impactos econômicos e socioambientais do modelo petroexportador acabaram por gerar considerável insatisfação entre a população. Como consequência, três presidentes - Abdalá Bucaram (1996-1997), Jamil Mahuad (1998-2000) e Lucio Gutiérrez (2003-2005) - foram depostos por pressão popular (Acosta et al., 2009).

Dentro desse contexto, a eleição de Correa foi construída como uma oportunidade para mudanças no modelo de desenvolvimento. O presidente anterior, Lucio Gutiérrez, assumiu o poder em 2003 e, até 2004, gozou de certa popularidade. A partir de então, começaram a ocorrer protestos na área rural, por conta de sua política econômica, e na cidade, devido a denúncias de corrupção (Espinosa 2013). Dessa forma, a candidatura de Correa recebeu apoio de uma ampla aliança, envolvendo movimentos indígenas, camponeses e organizações ambientalistas (Arsel \& Angel 2012). Dentre esses apoiadores, existiam muitos que defendiam a moratória da extração de petróleo na região de Yasuní; sendo esse tema amplamente debatido durante o período eleitoral, e posteriormente incorporado à campanha de Correa (Arsel \& Angel 2012; Espinosa 2013).

Conforme mencionado anteriormente, a extração de petróleo no Equador é associada ao regime neoliberal e a um período de aumento da dívida externa do país. Segundo Davidov (2012), Correa buscava caracterizar seu governo como "pós-neoliberal" e abandonar o modelo econômico vigente. Assim, havia interesse político em desafiar o setor petroleiro, mostrando-se independente das 
estratégias desenhadas pelo Banco Mundial e pelo FMI. Para tanto, ele buscou reverter a tendência neoliberal, revisar os contratos de concessão de petróleo e aumentar a participação do Estado no setor (Acosta et al., 2009).

Ao mesmo tempo, o amplo debate que vinha sendo feito sobre mudanças climáticas permitiria ao Equador, por meio da Iniciativa, consolidar uma posição de liderança política, não apenas regional, mas também globalmente (Acosta et al., 2009). Além disso, a defesa da proposta dava legitimidade interna ao presidente Correa. Por exemplo, em momentos em que era criticado por movimentos por direitos humanos, o governo utilizava a Iniciativa para mostrar como levava a sério a questão dos povos isolados (Espinosa 2013).

\section{III.3. A abertura e o fechamento da janela de políticas públicas}

Após a apresentação pública de 2005, a Iniciativa Yasuní-ITT teve considerável aceitação entre movimentos sociais dentro e fora do Equador. Para essa ampla aprovação, foi muito importante a rede que se formou em torno da proposta. Nesse sentido, o triplo discurso sobre preservação da biodiversidade, respeito aos povos tradicionais e mitigação das mudanças climáticas ampliou consideravelmente a base de apoio em torno da proposta.

Como forma de divulgar a Iniciativa, diferentes campanhas nacionais e internacionais foram criadas pelas redes de ONGs que a defendiam, tais como Amazonía por la Vida e Yasuní depende de ti (Espinosa 2013). Outra estratégia foi a responsabilização dos consumidores; nesse sentido, pessoas em diferentes países eram convidadas a diminuir seu consumo de petróleo como forma de apoiar a resistência em Yasuní. Da mesma forma, durante algum tempo, foi possível que indivíduos comprassem Certificados de Garantía Yasuní (CGY) pela internet, como forma a fortalecer um eventual fundo de manutenção do petróleo no subsolo (Rival 2010).

Depois de sua eleição, Correa convidou algumas pessoas que defendiam a Iniciativa para seu governo, o que facilitou a transformação da proposta em uma política de governo (Arsel \& Angel 2012; Espinosa 2013). Logo após sua indicação para o Ministério de Energia e Minas (MEM), o economista Alberto Acosta, um dos defensores da Iniciativa, foi pressionado por movimentos sociais a levar adiante a proposta e, em janeiro de 2007, o MEM fez a proposição formal. $\mathrm{O}$ fato de ter sido apresentada pelo próprio setor energético chamou ainda mais a atenção para a Iniciativa. Em abril do mesmo ano, o presidente Correa validou a Iniciativa, afirmando que sua administração preferia que o petróleo dos campos ITT fosse mantido no subsolo permanentemente, desde que tal ação fosse compensada pela comunidade internacional.

A Iniciativa foi oficializada em junho de 2007, decidindo, ao menos temporariamente, a disputa política que vinha sendo travada entre o MEM e a Petroecuador, que defendia a exploração dos poços. A partir de então, representantes do governo passaram a promover a Iniciativa em diferentes fóruns internacionais, como o Encontro das Nações Unidas sobre o Clima, em Nova York (2007); a Conferência das Partes (COP 13), em Bali (2007); e diferentes encontros da OPEP (Acosta 2009; Acosta et al., 2009; Finer et al., 2009; Espinosa 2013).

Entretanto, a operacionalização da Iniciativa se mostrou mais complexa e polêmica do que era esperado, principalmente devido à necessidade de se chegar a uma medida mais precisa do "valor" do petróleo e à dificuldade de se operacionalizar um fundo internacional para esse fim. A ideia original de um sistema de troca de dívida foi, posteriormente, substituída pela emissão de créditos de carbono. Todavia, o caso do Equador não se enquadrava como Mecanismo de Desenvolvimento Limpo, uma vez que a Iniciativa se baseava no 
cálculo de "emissões líquidas evitadas", uma categoria não prevista no Protocolo de Quioto (Moncayo 2011). Ao mesmo tempo, essa tentativa recebeu críticas de movimentos sociais. Assim, foi proposta a emissão de Certificados de Garantía Yasuní, um mecanismo que não estaria vinculado ao Protocolo de Quioto, mas que, esperava-se, poderia ser negociado no Sistema de Negociação de Emissões da União Europeia (EU Emissions Trading System). Esta confusão no desenho do projeto fez com que sua operacionalização levasse um longo tempo, durante o qual houve mudanças significativas no contexto internacional (Acosta 2009; Finer et al., 2009).

Outro elemento que dificultou a operacionalização da Iniciativa Yasuní-ITT estava relacionado à atribuição de responsabilidade pelo seu encaminhamento dentro do governo. Em um primeiro momento, a Iniciativa ficou a cargo do MEM; entretanto, quando Acosta assumiu a presidência da Asamblea Constituyente, a Iniciativa foi transferida para uma secretaria, dentro do Ministerio de Relaciones Exteriores y Movilidad Humana. Quando chegou o prazo estipulado para o início das doações, o sistema de financiamento ainda não havia sido constituído. Dessa forma, o prazo foi estendido até dezembro de 2008 e a responsabilidade foi transferida para o Comité Administrativo y Directivo (CAD) (Espinosa 2013).

Apesar da demora em se estabelecer o funcionamento do sistema, a comunidade internacional continuou, em parte, a apoiá-lo. Alemanha e Espanha expressaram interesse em financiar a Iniciativa com US\$ 50 milhões e US\$ 20 milhões, respectivamente (Espinosa 2013; Finer et al., 2009). Entretanto, à medida que o tempo foi passando, vários dos prazos colocados pelo governo do Equador expiraram, sem que se conseguisse efetivamente obter o valor total esperado. Durante esse período, Correa ameaçou, diversas vezes, levar adiante a exploração do petróleo caso a proposta não recebesse os recursos esperados (Acosta 2014; Finer et al., 2009).

Essa preocupação intransigente com as compensações foi um elemento de afastamento entre o governo e os movimentos sociais. Por um lado, na perspectiva do governo, a Iniciativa parecia ter sido reduzida à compensação financeira. Por outro lado, ONGs e movimentos sociais, como Acción Ecológica e Oilwatch, defendiam que os benefícios sociais e ambientais da conservação de Yasuní eram importantes por si só e que o Equador deveria levar adiante a Iniciativa, independentemente do volume de recursos obtidos.

Além disso, apesar de reconhecerem a importância da compensação, de forma geral, os movimentos associados à campanha Amazonía por la Vida se colocavam contrários a um sistema de valoração e mercantilização da natureza. Assim, não aceitavam que as compensações fossem vinculadas ao Protocolo de Quioto, nem que fossem caracterizadas como Pagamento por Serviços Ambientais. Ao mesmo tempo, a questão da soberania política do Equador era uma questão sensível. O que se esperava era que a manutenção do petróleo no subsolo fosse uma política pública nacional desenvolvida em coincidência com interesses internacionais, e não que a política fosse ajustada aos critérios de fundos criados por países ricos (Acosta 2009; Acosta et al., 2009).

Outra situação que estremeceu as relações entre movimentos sociais e o governo foi a forma como este tratou a exploração de petróleo em Yasuní, que, segundo Acosta (2009), "beirava a esquizofrenia". Embora o governo tivesse assumido, já em sua campanha, a proposta de não explorar os campos ITT, em 2007 foram assinados memorandos de entendimento com quatro empresas transnacionais para a exploração do campo. Em outubro do mesmo ano, o governo concedeu à Petrobrás licença ambiental para explorar o bloco 31, vizinho aos campos ITT e também dentro do PNY e da REW (Espinosa 2013; Finer et al., 2009). Nesse sentido, há autores que sugerem que, apesar de o 
governo perceber uma oportunidade política com a defesa da Iniciativa, não havia o real interesse em seu sucesso (Chiriboga 2010).

Por fim, a indecisão sobre a operacionalização do sistema e a exigência da compensação econômica acabou por reduzir o interesse dos países industrializados. Somente em 2010, o governo do Equador e o Programa das Nações Unidas para o Desenvolvimento (PNUD) assinaram um convênio para a administração de um fundo internacional, onde as contribuições pudessem ser depositadas. Neste momento, posterior à crise de 2008 e ao recuo dos governos de diferentes países com relação a planos de mitigação das mudanças climáticas no âmbito da UNFCCC, o interesse pela proposta havia se reduzido. Por exemplo, em 2011, a Alemanha reviu sua decisão, argumentando que a experiência poderia incentivar outros países a só desenvolverem atividades de conservação à biodiversidade no caso de financiamento externo (Espinosa 2013). Com essa mudança no cenário internacional, o governo equatoriano retirou seu apoio à Iniciativa e, em 2013, Correa anunciou que iria autorizar a exploração dos campos ITT.

A decisão do governo iniciou uma nova etapa no desenrolar da Iniciativa Yasuní-ITT. Como resposta, movimentos sociais passaram a cobrar do governo sua implementação e, para tanto, pressionar pela realização de uma consulta popular sobre a opção de não se explorar os campos ITT, independentemente dos recursos internacionais. Entretanto, com a janela de políticas públicas internacional fechada, o governo equatoriano passou a demonstrar menos interesse pela Iniciativa (Acosta 2014).

\section{Conclusões}

Ao longo do texto, buscou-se, utilizando o MFM, fazer uma análise do desenvolvimento e tentativa de implementação da Iniciativa Yasuní-ITT. O modelo se mostrou eficaz para destacar particularidades do caso, destacando elementos referentes à formulação do problema, contexto e atuação dos atores que ajudam a entender como a Iniciativa ganhou espaço na agenda de políticas públicas equatoriana. Além disso, como contribuição conceitual, a análise apresentada indica novos elementos para o debate sobre o uso do MFM na descrição de casos empíricos. Dessa forma, ela indica a possibilidade de se mesclar discursos de natureza moral e econômica na definição dos problemas, as oportunidades associadas à convergência do fluxo político doméstico e internacional e a importância da mobilidade de agentes entre diferentes espaços políticos.

Com relação à formulação do problema, a Iniciativa Yasuní-ITT mostrou a potencialidade de estratégias que mesclem diferentes discursos e perspectivas. Dessa forma, a fusão de argumentos de conservação de biodiversidade, direitos humanos e mitigação das mudanças climáticas, em conjunto com ganhos econômicos, conseguiu criar um discurso forte o suficiente que se sobrepôs, mesmo que temporariamente, ao pensamento hegemônico exclusivamente extrativista (Espinosa 2013). Nesse sentido, o exemplo mostra que somente o uso de retóricas morais (proteção à biodiversidade e defesa de povos isolados) pode não ser suficiente para mobilizar agentes de um governo de cunho neoextrativista ou neodesenvolvimentista, sendo a inclusão de uma retórica econômica mais eficaz nesta mobilização (Hannigan 1995). Assim, o exemplo diverge do argumento de Zahariadis (2007) quando este minimiza a importância da persuasão pela construção dos problemas na mudança de posição dos tomadores de decisão. No caso estudado, persuasão e construção de identidade foram elementos cruciais na abertura e no fechamento da janela de política pública, o que sugere que há ganhos em se usar, de forma complementar, o MFM com perspectivas construtivistas. 
Um segundo elemento diz respeito à relação entre fluxo político nos níveis nacional e internacional. Considerando o contexto nacional, o apoio dado à Iniciativa pode ser relacionado à insatisfação da população com o modelo de desenvolvimento baseado na extração do petróleo e no modelo neoliberal, bem como à eleição de um presidente que se opunha a tal modelo. Ao mesmo tempo, o aprofundamento do debate sobre mudanças climáticas nos fóruns internacionais, em particular as elevadas expectativas em 2009 com a Conferência das Partes (COP 15), sobre a criação de novos instrumentos de mitigação da emissão de GEE, foram fundamentais para uma maior legitimidade da proposta junto à sociedade equatoriana e à comunidade internacional. Entretanto, o caso mostra uma forte correlação entre os fluxos nacional e internacional. Depois que os países industrializados desistiram de apoiar financeiramente a Iniciativa, o governo Correa anunciou que iria permitir a exploração dos campos ITT, fechando a janela de políticas públicas. Na proposta original de Kingdon (1984), existe referência ao "humor nacional"; todavia, no contexto de algumas políticas específicas, a inclusão do "humor internacional" nas análises também parece se fazer necessária.

Por fim, outro elemento que auxiliou a incorporação da Iniciativa pelo governo foi a mobilidade dos agentes sociais. O MFM destaca o papel de diferentes agentes na condução dos três fluxos, na abertura das janelas de políticas públicas e na definição das agendas. Entretanto, o modelo proposto por Kingdon (1984) se mostra um tanto rígido em analisar separadamente agentes de "dentro" e de "fora" do governo. O estudo da Iniciativa Yasuní-ITT, por sua vez, mostra que esses agentes não são estáticos e, dependendo do momento, atuam em diferentes meios, mudando sua capacidade de influência. Neste caso em particular, o convite para Alberto Acosta e Maria Fernanda Espinoza para integrarem o governo parece ter sido fundamental para garantir a legitimidade da Iniciativa e sua inclusão na agenda governamental.

Para além da discussão conceitual, o artigo ainda se propõe como motivador do aprofundamento do debate sobre atividades extrativas minerais no Brasil. A política econômica brasileira dos anos 2000 já foi caracterizada como uma combinação de práticas neodesenvolvimentistas e neoextrativistas, com significativos impactos sobre o meio ambiente e grupos sociais específicos (Milanez $\&$ Santos 2013). Dentro desse contexto, debater propostas de desenvolvimento pós-extrativistas como a Iniciativa Yasuní-ITT apresenta-se como uma oportunidade para questionar e relativizar o atual modelo de desenvolvimento do país.

Bruno Milanez (bruno.milanez@ufjf.edu.br) é Doutor em Política Ambiental pela Lincoln University (EUA) e Professor no Programa de Pós-graduação em Geografia e no Departamento de Produção e Mecânica da Universidade Federal de Juiz de Fora (UFJF). Vínculo Institucional: Departamento de Produção e Mecânica, UFJF, Juiz de Fora, MG, Brasil.

Rodrigo Salles Pereira dos Santos (santosrodrigosp@gmail.com) é Doutor em Ciências Humanas (Sociologia) pela Universidade Federal do Rio de Janeiro (UFRJ), Professor do Programa de Pós-graduação em Sociologia e Antropologia (PPGSA) e do Departamento de Sociologia da mesma universidade. Vínculo institucional: Departamento de Sociologia, UFRJ, Rio de Janeiro, RJ, Brasil.

\section{Referências}

Acosta, A., 2000. El petróleo en el Ecuador: una evaluación crítica del pasado cuarto de siglo. In ed. El Ecuador post petrolero. Quito: Acción Ecológica.

, 2009. La maldición de la abundancia. Quito: Comité Ecuménico de Proyectos CEP/Ediciones Abya-Yala. , 2011. Extractivismo y neoextractivismo: dos caras de la misma maldición. In Grupo Permanente de Trabajo sobre Alternativas Al Desarrollo, ed. Más alla del desarrollo. Quito: AbyaYala/Fundación Rosa Luxemburg. , 2014. La difícil construcción de la utopía. Disponível em: http://www.rebelion.org/noticia.php?id = 180285\&titular=la-dif\%EDcil-construcci\%F3n-de-la-utop\%EDa. Acesso em: 4 jul. 2016. 
Acosta, A.; Gudynas, E.; Martínez, E. \& Vogel, J., 2009. Dejar el crudo en tierra o la búsqueda del paraíso perdido. Elementos para una propuesta política y económica para la Iniciativa de no explotación del crudo del ITT. Polis, 8, pp.429-452. DOI: 10.4067/s0718-65682009000200019

Arsel, M. \& Angel, N.A., 2012. "Stating” Nature's Role in Ecuadorian Development: Civil Society and the Yasuní-ITT Initiative. Journal of Developing Societies, 28(2), pp.203-227. DOI: 10.1177/0169796x12448758

Bachrach, P. \& Baratz, M.S., 2011. Duas faces do poder. Revista de Sociologia e Política, 19(40), pp.149-157. DOI: 10.1590/s0104-44782011000300011

Bebbington, A. \& Bebbington, D.H., 2010. An Andean Avatar: Post-Neoliberal and Neoliberal Strategies for Promoting Extractive Industries. Manchester: Brooks World Poverty Institute/University of Manchester.

Bellettini, O. \& Ordóñez, A., 2011. Translating Evidence into Policies: Two Cases in Ecuador. Quito: Grupo Faro.

Bendor, J.; Moe, T.M. \& Shotts, K.W., 2001. Recycling the Garbage Can: An Assessment of the Research Program. The American Political Science Review, 95, pp.169-190.

Birkland, T.A., 2007. Agenda Setting in Public Policy. In F. Fischer; G.K. Miller \& M.S. Sidney, eds. Handbook of Public Policy Analysis: Theory, Politics, and Methods. Boca Raton: CRC Press. , 2015. An Introduction to the Policy Process: Theories, Concepts and Models of Public Policy Making. London: Routledge.

Capella, A.C.N., 2007. Perspectivas teóricas sobre o processo de formulação de políticas públicas. In: G. Hochman; M. Arretche \& E. Marques, eds. Políticas públicas no Brasil. Rio de Janeiro: Editora Fiocruz.

, 2010. Transformando idéias em ação: o papel dos empreendedores de políticas públicas In $34^{\circ}$ Encontro Anual da Anpocs. Caxambu.

Chen, Z., 2011. Is the Policy Window Open for High-Speed Rail in the United States: A Perspective from the Multiple Streams Model of Policymaking. Transportation Law Journal, 38, pp.115-144.

Cohen, M.D.; March, J.G. \& Olsen, J.P., 1972. A Garbage Can Model of Organizational Choice. Administrative Science Quarterly, 17, pp.1-25. DOI: 10.2307/2392088

Davidov, V., 2012. Saving Nature or Performing Sovereignty? Ecuador's Initiative to 'Keep Oil in the Ground'. Antropology Today, 28, pp.12-15. DOI: 10.1111/j.1467-8322.2012.00872.x

Donziger, S.R., 2004. Rainforest Chernobyl: Litigating Indigenous Rights and the Environment in Latin America. Human Rights Brief, 11(2), pp.1-4. DOI: 10.1079/9781845931247.0067

Espinosa, C., 2013. The Riddle of Leaving the Oil in the Soil - Ecuador's Yasuní-ITT Project from a Discourse Perspective. Forest Policy and Economics, 36, pp.27-36. DOI: 10.1016/j.forpol.2012.07.012

Finer, M.; Vijay, V.; Ponce, F.; Jenkins, C.N. \& Kahn, T.R., 2009. Ecuador's Yasuní Biosphere Reserve: A Brief Modern History and Conservation Challenges. Environmental Research Letters, 4(3). DOI: 10.1088/1748-9326/4/3/034005

Gottems, L.B.D.; Pires, M.R.G.M.; Calmon, P.C.D.P. \& Alves, E.D., 2013. O modelo dos múltiplos fluxos de Kingdon na análise de políticas de saúde: aplicabilidades, contribuições e limites. Saúde e Sociedade, 22, pp.511-520. DOI: 10.1590/s0104-12902013000200020

Gudynas, E., 2009. Diez tesis urgentes sobre el nuevo extractivismo. In: CAAP \& CLAES, eds. Extractivismo, política y sociedad. Quito: Centro Andino de Acción Popular.

Hannigan, J.A., 1995. Environmental Sociology: A Social Constructionist Perspective. London: Routledge.

Howlett, M. \& Ramesh, M., 2003. Studying Public Policy: Policy Cycles and Policy Subsystems. New York: Oxford University Press.

Jann, W. \& Wegrich, K., 2007. Theories of the Policy Cycle. In F. Fischer; G.J. Miller \& M.S. Sidney, eds. Handbook of Public Policy Analysis: Theory, Politics, and Methods. Boca Raton: CRC Press.

Khayesi, M. \& Amekudzi, A.A., 2011. Kingdon's Multiple Streams Model and Automobile Dependence Reversal Path: The Case of Curitiba, Brazil. Journal of Transport Geography, 19, pp.1547-1552. DOI: 10.1016/j.jtrangeo.2011.06.012

Kingdon, J.W., 1984. Agendas, Alternatives, and Public Policies. Boston: Harper Collins Publishers.

Kokubo, C., 2013. Brasil: Mineração em terra indígena pode ser aprovada em 2013. Disponível em: http://www.oeco.org.br/reportagens/26919-brasil-mineracao-em-terra-indigena-pode-ser-aprovada-em-2013 Acesso em: 4 jul. 2016.

Larrea, C., 2010. Petróleo o conservación en el Parque Yasuní: una opción histórica. Quito: Universidad Andina Simón Bolívar.

Larrea, C.; Vásconez, A. \& Greene, N., 2008. Informe de apoyo: indicadores económicos sociales y ambientales básicos del Ecuador. Quito: Comisión para la Auditoria Integral del Crédito Público.

Lasswell, H.D., 1956. The Decision Process: Seven Categories of Functional Analysis. College Park: University of Maryland Press.

Leroy, J.P. \& Malerba, J., 2005. Petrobras: ¿Integración o explotación? Rio de Janeiro: Fase/Projeto Brasil Sustentável e Democrático.

Lukes, S., 2005. Power: A Radical View. New York: Palgrave Macmillan.

Malerba, J., 2012. Novo marco legal da mineração no Brasil: para quê? Para quem? Rio de Janeiro: Fase.

Martin, P.L., 2011. Global Governance from the Amazon: Leaving Oil Underground in Yasuní National Park, Ecuador. Global Enviornmental Politics, 11, pp.22-42. DOI: 10.1162/glep_a_00082

Martínez, E., 2000. Moratoria a la actividad petrolera. In A. Acosta, ed. El Ecuador post petrolero. Quito: Acción Ecológica. 
McMaster, A., 2009. Policy Making in UK sport: An Examination of the Role and Influence of the Minister for Sport. Tese de Doutorado. Loughborough: Loughborough University.

Melo, M.; Figueroa, I. \& Wray, N., 2009. Consultoria para el estudio de los aspectos jurídico constitucionales de la propuesta ITT. United Nations Development Programme.

Milanez, B., 2014. Equador: deixar o petróleo no subsolo. In J. Malerba, ed. Diferentes formas de dizer não. Experiências internacionais de resistência, restrição e proibição ao extrativismo mineral. Rio de Janeiro: Fase.

Milanez, B. \& Santos, R.S.P., 2013. Neoextrativismo no Brasil? Uma análise da proposta do novo marco legal da mineração. Revista Pós Ciências Sociais, 10(19), pp.119-148.

Moncayo, M.G., 2011. Yasuní - ITT Initiative: A Different Conservation Proposal. Comparative Analysis with the Clean Development Mechanism under the Kyoto Protocol. Tese de Doutorado. Santiado de Chile: Universidad de Chile/Universität Heidelberg.

Motta, A.R.P.; Borges, C.P.; Kiperstok, A.; Esquerre, K.P.; Araujo, P.M. \& Branco, L. D.P.N., 2013. Tratamento de água produzida de petróleo para remoção de óleo por processos de separação por membranas: revisão. Engenharia Sanitaria e Ambiental, 18(1), pp.15-26. DOI: 10.1590/s1413-41522013000100003

Mucciaroni, G., 1992. The Garbage Can Model \& the Study of Policy Making: A Critique. Polity, 24, pp.459-482. DOI: 10.4324/9780203097571.ch24

Nagem, F.A. \& Silva, S.P., 2013. Institucionalização e execução das políticas públicas de economia solidária no Brasil. Revista de Sociologia e Política, 21(46), pp.159-175. DOI: 10.1590/s0104-44782013000200010

Ordoñez, A., 2013. Defining Problems or Providing Solutions? The Role of Ideas in Policy Debates. Disponível em: http://www.politicsandideas.org/wp-content/uploads/2014/09/PI-Defining-problems.pdf Acesso em: 4 jul. 2016.

Bellettini, O. \& Ordoñez, A., 2013. Ecuador: del país recursos al país conocimiento. Quito: Grupo Faro.

Pereira, M.C.G. \& Teixeira, M.A.C., 2011. A inclusão de catadores em programas de coleta seletiva: da agenda local à nacional. Cadernos EBAPE.BR, 9, pp.895-913.

Pinto, I.C.M., 2008. Mudanças nas políticas públicas: a perspectiva do ciclo de política. Revista de Políticas Públicas, 12, pp.27-36.

Redclift, M.R. \& Woodgate, G., 2010. The International Handbook of Environmental Sociologyi. Cheltenham: Edward Elgar.

Reed, P., 2011. REDD+ and the Indigenous Question: A Case Study from Ecuador. Forests, 2(4), pp.525-549. DOI: 10.3390/f2020525

Rival, L., 2010. Ecuador's Yasuní-ITT Initiative: The Old and New Values of Petroleum. Ecological Economics, 70, pp.358-365.

Sager, F. \& Rielle, Y., 2013. Sorting through the Garbage Can: Under What Conditions Do Governments Adopt Policy Programs? Policy Sciences, 46(1), pp.1-21. DOI: 10.1007/s11077-012-9165-7

Souza, C., 2006. Políticas públicas: uma revisão da literatura. Sociologias, 16, pp.20-45. DOI: 10.1590/s1517-45222006000200003

Temper, L.; Yánez, I.; Sharife, K.; Ojo, G. \& Martinez-Alier, J., 2013. Towards a Post-Oil Civilization Yasunization and other Initiatives to Leave Fossil Fuels in the Soil. Environmental Justice Organisations, Liabilities and Trade.

Zahariadis, N., 2007. The Multiple Streams Framework: Structure, Limitations, Prospects. In P.A. Sabatier, ed. Theories of the policy process. Cambridge, MA: Westview Press.

Zahariadis, N. \& Allen, C.S., 1995. Ideas, Networks, and Policy Streams: Privatization in Britain and Germany. Policy Studies Review, 14(1-2), pp.71-98. DOI: 10.1111/j.1541-1338.1995.tb00622.x

\section{Artigos de jornais}

Chiriboga, M., 2010. Lágrimas por ITT. El Universo, 23 Jan.

Guerrero, M., 2011. Sobre los ecológicos. El Diário, 23, Ago.

\section{Outras fontes}

Acción Ecológica, 2014. Mapas de Acción Ecológica. Disponível em: http://mapas.accionecologica.org/. Acesso em: 4 jul. 2016.

Amazonía Por La Vida. 2015. Quiénes somos - Contactos. Disponível em: http://www.amazoniaporlavida.org/es/quissomos-contactos.html. Acesso em: 4 jul. 2016.

Amazonia Por La Vida \& Grupo Nacional Contra La Deuda De Ecuador. 2009. Yasuní: justicia ambiental sin deuda ilegítima. Disponível em: http://www.gloobal.net/iepala/gloobal/fichas/ficha.php?id = 7925\&entidad=Textos\&html = 1 . Acesso em 4 jul. 2016.

BBC, 2014. US Judge Annuls Ecuador Oil Ruling against Chevron. Disponível em: http://www.bbc.com/news/worldlatin-america-26441836. Acesso em: 4 jul. 2016.

CNDTM, 2013. Texto base. Brasília: Comitê Nacional em Defesa dos Territórios frente à Mineração.

EIA 2014. Ecuador. Washington, DC: U.S. Energy Information Agency.

LLACTA, 2006. Moratoria al Proyecto ITT y Bloque 31. Disponível em: http://www.llacta.org/textos/yasuni010.pdf. Acesso em: 4 jul. 2016.

Oilwatch, 2007. Opcion 1: Conservación de crudo en el subsuelo. Quito: Oilwatch. 
República del Ecuador, 2008. Constitución de la República del Ecuador. Quito: Asamblea Constituyente.

UICN \& CEC, 2010. Propuesta para la consultoría 'Programa de Educación para el Desarrollo Sostenible de la Reserva de Biósfera Yasuní. Quito: Unión Internacional para la Conservación de la Naturaleza/Comisión de Educación y Comunicación.

World Bank, 2013. Data. Disponível em: http://data.worldbank.org. Acesso em: 4 jul. 2016. 2014. World Bank Commodity Price Data. Washington, DC: World Bank.

The Yasuní-ITT Initiative: an analysis based on the Multiple Stream Model

\begin{abstract}
This paper analyzes the Yasuní-ITT Initiative, a proposed environmental and natural resources policy, by which the Ecuadorian government would renounce the exploitation of major oil reserves. It aims at discussing the Initiative as an innovation on the political agenda based on the social construction of oil exploitation in the Ecuadorian Amazon as a public problem, the development of alternative solutions and their government recognition. The research is grounded on the Kingdon's Multiple Streams Model (MSM) in the agenda setting process, from an extensive literature review. The data concerning the Initiative was collected primarily on scientific literature, as well as documents of institutions and organizations involved in its formulation. Although the Initiative has not been implemented, its evolution in the agenda has highlighted the links between local, territorial disputes and national economic issues, the possibility of economic compensation and a moratorium on exploitation, as well as raising questions concerning political legitimacy. These flows' linkage was possible through a political window centered on climate change and varied agents such as the Presidency, oil companies, NGOs and social movements, as well as international institutions and other governments. The main contributions to the discussion of public policy and agenda setting concern: the relevance of the combination of discourses, moral (biodiversity, human rights and climate change) and economic in this case; the strong correlation between different scales (national and international) in understanding the political flow; and the procedural view of agents in leading flows and policy windows, by changing their relative capabilities of exercising power.
\end{abstract}

KEYWORDS: public policy, Multiple Streams Model, oil, Ecuador, Yasuní.

This is an Open Access article distributed under the terms of the Creative Commons Attribution Non-Commercial License which permits unrestricted non-commercial use, distribution, and reproduction in any medium provided the original work is properly cited. 